\title{
PIK3CA mutations enable targeting of a breast tumor dependency through mTOR-mediated MCL-1 translation
}

2016 @) The Authors, some rights reserved. exclusive licensee American Association for the Advancement of Science.

\author{
Grace R. Anderson, ${ }^{1}$ Suzanne E. Wardell, ${ }^{1}$ Merve Cakir, ${ }^{1,2}$ Lorin Crawford, $^{1,3}$ Jim C. Leeds, $^{1}$ \\ Daniel P. Nussbaum, ${ }^{1,4}$ Pallavi S. Shankar, ${ }^{1}$ Ryan S. Soderquist, ${ }^{1}$ Elizabeth M. Stein, ${ }^{1}$ \\ Jennifer P. Tingley, ${ }^{1}$ Peter S. Winter, ${ }^{1,5}$ Elizabeth K. Zieser-Misenheimer, ${ }^{1}$ Holly M. Alley, ${ }^{1}$ \\ Alexander Yllanes, ${ }^{1}$ Victoria Haney, ${ }^{1}$ Kimberly L. Blackwell, ${ }^{6}$ Shannon J. McCall, ${ }^{7}$ \\ Donald P. McDonnell, ${ }^{1}$ Kris C. Wood ${ }^{1}$ *
}

Therapies that efficiently induce apoptosis are likely to be required for durable clinical responses in patients with solid tumors. Using a pharmacological screening approach, we discovered that combined inhibition of B cell lymphomaextra large (BCL- $\mathrm{X}_{\mathrm{L}}$ ) and the mammalian target of rapamycin (mTOR)/4E-BP axis results in selective and synergistic induction of apoptosis in cellular and animal models of PIK3CA mutant breast cancers, including triple-negative tumors. Mechanistically, inhibition of mTOR/4E-BP suppresses myeloid cell leukemia-1 (MCL-1) protein translation only in PIK3CA mutant tumors, creating a synthetic dependence on $B C L-X_{L}$. This dual dependence on $B C L-X_{L}$ and $M C L-1$, but not on BCL-2, appears to be a fundamental property of diverse breast cancer cell lines, xenografts, and patient-derived tumors that is independent of the molecular subtype or PIK3CA mutational status. Furthermore, this dependence distinguishes breast cancers from normal breast epithelial cells, which are neither primed for apoptosis nor dependent on $B C L-X_{L} / M C L-1$, suggesting a potential therapeutic window. By tilting the balance of pro- to antiapoptotic signals in the mitochondria, dual inhibition of MCL-1 and BCL- $X_{L}$ also sensitizes breast cancer cells to standard-of-care cytotoxic and targeted chemotherapies. Together, these results suggest that patients with PIK3CA mutant breast cancers may benefit from combined treatment with inhibitors of $B C L-X_{L}$ and the mTOR/4E-BP axis, whereas alternative methods of inhibiting MCL-1 and $\mathrm{BCL}-\mathrm{X}_{\mathrm{L}}$ may be effective in tumors lacking PIK3CA mutations.

\section{INTRODUCTION}

Cancers are characterized by genetic and epigenetic alterations that cause disruption of normally balanced growth and survival processes, including those governing growth signaling, cell cycle regulation, and apoptosis (1). Growth signaling and cell cycle pathways have been pharmacologically targeted with some success, but the effectiveness of these strategies has been limited by incomplete and transient therapeutic responses $(2,3)$. Given this limitation, together with the fact that curative chemotherapies have historically been associated with selective, potent induction of apoptosis in tumors, there is a strong interest in developing strategies to directly target apoptotic pathways in cancer cells (4-6).

Cell-intrinsic apoptosis is a tightly regulated process that is controlled by the balance of pro- and antiapoptotic proteins in the mitochondria $(6,7)$. There has been a focused effort in the past decade to develop small-molecule inhibitors of the B cell lymphoma-2 (BCL-2) family proteins [such as BCL-extra large (BCL- $\left.\mathrm{X}_{\mathrm{L}}\right)$, BCL-2, and myeloid cell leukemia-1 (MCL-1)] - the key antiapoptotic proteins in the mitochondria-on the basis of the observation that some cancer cells may be particularly "primed" for apoptosis relative to nonmalignant cells $(6,8)$. BH3 mimetics, drugs that specifically bind and inhibit BCL-2 antiapoptotic proteins, are currently being explored as singleagent therapies for the treatment of hematologic malignancies. The ob-

\footnotetext{
${ }^{1}$ Department of Pharmacology and Cancer Biology, Duke University, Durham, NC 27710, USA. Program in Computational Biology and Bioinformatics, Duke University, Durham, NC 27708, USA. ${ }^{3}$ Department of Statistical Science, Duke University, Durham, NC 27708, USA. ${ }^{4}$ Department of Surgery, Duke University, Durham, NC 27710, USA. ${ }^{5}$ Program in Genetics and Genomics, Duke University, Durham, NC 27710, USA. ${ }^{6}$ Department of Medicine/Oncology, Duke University, Durham, NC 27710, USA. ${ }^{7}$ Department of Pathology, Duke University, Durham, NC 27710, USA.

${ }^{*}$ Corresponding author. Email: kris.wood@duke.edu
}

servation that these cancers are particularly sensitive to the inhibition of specific BCL-2 family proteins supports this approach, and clinical trials in several indications have yielded substantial response rates in patients with relapsed or refractory disease $(4,9-12)$. Conversely, studies in various model systems suggest that the single-agent efficacy of $\mathrm{BH} 3 \mathrm{mi}$ metics in solid tumors, including breast cancers, is poor $(4,13,14)$. Thus, solid tumors may require combinatorial treatments that include $\mathrm{BH} 3$ mimetics together with agents that specifically sensitize cancer cells to their activity by shifting the balance of pro- to antiapoptotic signals ("priming" the cells), creating synthetic dependencies on specific BCL-2 family members.

One such class of agents that may be useful for priming solid tumors to create synthetic lethal dependencies on BCL-2 family proteins are phosphatidylinositol 3-kinase (PI3K)/mammalian target of rapamycin (mTOR) pathway inhibitors (15). PI3K/mTOR pathway inhibitors are undergoing extensive clinical development for breast cancer; however, responses to these agents have generally been modest to date $(16,17)$. Thus, there is a strong clinical need for both biomarkers of sensitivity and combination approaches that can make these inhibitors more effective (18).

Here, we describe the development of a combinatorial small-molecule screening approach to identify treatments that sensitize solid tumors cells to $\mathrm{BH} 3$ mimetics, the application of which revealed a pharmacological strategy to target apoptosis in PIK3CA mutant breast cancers. Definition of the mechanisms underlying the efficacy of this drug combination revealed a tumor lineage-encoded dual dependency on BCL- $\mathrm{X}_{\mathrm{L}}$ and MCL1 that can be exploited to drive selective apoptosis induction in breast cancers from diverse molecular subtypes and genetic backgrounds as well as sensitize tumors to standard-of-care chemotherapies. 


\section{RESULTS}

Targeted therapies sensitize solid tumors to $\mathrm{BH} 3$ mimetics in a context-specific manner

We first evaluated the effectiveness of $\mathrm{BH} 3$ mimetics as single agents in tumor cells derived from a broad spectrum of tissue types. Using a dual BCL-2/BCL- $\mathrm{X}_{\mathrm{L}}$ inhibitor, ABT737, we tested 43 cancer cell lines representing 10 different cancer types (Fig. 1A). Although most cell lines derived from solid tumors were insensitive to ABT737 [growth inhibition of $50 \%\left(\mathrm{GI}_{50}\right)>1 \mu \mathrm{M}$ ], a reference pair of acute myeloid leukemia cell lines previously reported to be sensitive to BCL-2 inhibition (HL60 and MOLM13) was sensitive to this drug $\left(\mathrm{GI}_{50}<1 \mu \mathrm{M}\right)(19)$. A sensitivity threshold of $1 \mu \mathrm{M}$ was defined on the basis of evidence that complete BCL-2/BCL- $\mathrm{X}_{\mathrm{L}}$ inhibition is achieved at this dose (20). To assess the potential use of $\mathrm{BH} 3$ mimetics as single agents more broadly, we compiled the data from Cancer Cell Line Encyclopedia (CCLE) and noted in a panel of 660 cell lines that those sensitive to ABT263, a related dual BCL$2 / B C L-X_{L}$ inhibitor, were enriched for blood cancers, whereas cells derived from solid tumors were typically insensitive (Fig. 1B). Thus, our studies and those of others confirmed the lack of efficacy of $\mathrm{BH} 3 \mathrm{mi}$ metics as single agents in cellular models of diverse solid tumors.

Next, we sought to identify drugs that sensitize solid tumor cells to $\mathrm{BH} 3$ mimetics by altering their apoptotic priming states. Specifically, we focused on inhibitors of the PI3K/mTOR and mitogen-activated protein kinase (MAPK) pathways for three reasons: (i) these pathways are frequently deregulated in solid tumors; (ii) these pathways can be selectively targeted pharmacologically; and (iii) these pathways have the potential to directly regulate apoptotic priming through their inhibitory effects on the proapoptotic proteins as well as their activating effects on the BCL-2 family antiapoptotic proteins (15). A panel of cell lines derived from solid tumors was treated with ABT737 in combination with a dual $\mathrm{PI} 3 \mathrm{~K} / \mathrm{mTOR}$ inhibitor, BEZ235, or an extracellular signal-regulated kinase (ERK) inhibitor, VX-11e, to identify potentially useful drug combinations (Fig. 1, C and D, and fig. S1, A to D). Although most cell lines could not be sensitized to ABT737 through PI3K or MAPK pathway inhibition (with on-target inhibition confirmed by immunoblotting), four of the five lines most sensitized by ERK inhibition were derived from colorectal cancers (CRCs), and three of the five lines most sensitized by PI3K/mTOR inhibition were derived from breast cancers (Fig. 1, C and D, and fig. S1, A to D). Notably, the effects of ABT737 were antagonized by ERK or PI3K/mTOR inhibitors in a subset of cell lines, potentially owing to shared effects on downstream targets (15).

To assess the relative importance of BCL-2 and BCL- $\mathrm{X}_{\mathrm{L}}$ in the CRC cell lines, we treated these lines (COLO205, WiDr, CRC119, and CRC240) with a selective BCL-2 inhibitor, ABT199, or a selective BCL- $\mathrm{X}_{\mathrm{L}}$ inhibitor, WEHI-539, in the presence of dimethyl sulfoxide (DMSO) control or VX-11e. ERK inhibition sensitized these lines to BCL- $\mathrm{X}_{\mathrm{L}}$ inhibition but not BCL-2 inhibition (Fig. 2, A and B). Each of these lines harbored a $K R A S$ or $B R A F$ activating mutation, in agreement with a recent report that used a pooled short hairpin RNA (shRNA) screening approach to identify synergy between MEK and BCL-X $\mathrm{L}_{\mathrm{L}}$ inhibition in KRAS mutant cancers (21). Using a similar approach, we assessed the effects of BCL-2 and $\mathrm{BCL}-\mathrm{X}_{\mathrm{L}}$ inhibition in the presence of BEZ235 in the subset of sensitized breast cancer (BC) cell lines, revealing that sensitization in this context is also dependent only on inhibition of BCL- $\mathrm{X}_{\mathrm{L}}$ (Fig. 2, C and D).

PIK3CA mutant tumors treated with inhibitors of $\mathrm{PI3K} / \mathrm{mTOR}$ and $B C L-X_{L}$ undergo apoptosis

To better define the landscape of therapeutic efficacy between PI3K/ mTOR and BCL- $\mathrm{X}_{\mathrm{L}}$ inhibitors in breast cancer, we tested this drug combination on a panel of 19 cell lines that model breast cancers exhibiting diverse genetic and histological features. Sensitivity to the combination of WEHI-539 and BEZ235 tracked strongly with the presence of canonical PIK3CA activating mutations, but not with HER2, PTEN, or luminal/basal status, or with steady-state AKT phosphorylation status in cells cultured in normal growth medium (cell lines were annotated as PIK3CA mutant if they contained canonical activating mutations at residues E542, E545, or H1027; Fig. 3, A and B, fig. S2, A to $\mathrm{D}$, and table $\mathrm{S} 1$ ). The effects of combined PI3K/mTOR and BCL- $\mathrm{X}_{\mathrm{L}}$ inhibition were associated with submicromolar drug sensitivity in growth assays and required expression of the activator BCL-2 family proteins BIM and BID, but not PUMA, consistent with the canonical roles of these proteins in mitochondrial apoptosis regulation (fig. S2E and table S2) $(6,22)$. Sensitivity in growth assays correlated with apoptosis induction in PIK3CA mutant breast cancer cell lines, with little to no effect in PIK3CA wild-type (WT) cell lines (Fig. 3C and fig. S2F). To assess the in vivo efficacy of combined BCL- $\mathrm{X}_{\mathrm{L}}$ and PI3K/mTOR inhibition, we used an orthotopic xenograft model of PIK3CA mutant triple-negative breast cancer (TNBC) (BT-20). In this model, the combination of low-dose PI3K/mTOR inhibition (BEZ235, $10 \mathrm{mg} \mathrm{kg}^{-1} \mathrm{day}^{-1}$ ) and dual BCL-2/BCL- $\mathrm{X}_{\mathrm{L}}$ inhibition (ABT737, $25 \mathrm{mg} \mathrm{kg}^{-1}$ day ${ }^{-1}$ ) yielded tumor regressions, whereas each individual agent only modestly affected tumor growth (Fig. 3, D and E, and table S3).

\section{PI3K/mTOR inhibition cooperates with $B C L-X_{L}$ inhibition through suppression of MCL-1}

Having established the therapeutic efficacy of PI3K/mTOR plus BCL$\mathrm{X}_{\mathrm{L}}$ inhibition, we sought to undercover the mechanism(s) by which the observed sensitivity is achieved. To gain insight into the overall apoptotic priming states as well as the specific BCL-2 family dependencies in PIK3CA mutant breast cancers, we performed $\mathrm{BH} 3$ profiling on PIK3CA mutant breast cancer cell lines. Briefly, $\mathrm{BH} 3$ profiling is an assay that measures depolarization in isolated mitochondria in response to the addition of short peptides that mimic the activity of BCL-2 family proteins. These assays revealed that PIK3CA mutant cell lines were highly primed to undergo apoptosis, as evidenced by strong mitochondrial outer membrane depolarization after treatment with a low concentration of the BIM peptide $(1 \mu \mathrm{M}$, where typical assay concentrations range from 10 to $100 \mu \mathrm{M}$ ) (Fig. 4A) (8). Furthermore, these cell lines were dependent on both BCL- $\mathrm{X}_{\mathrm{L}}$ and MCL-1, but not BCL-2, as indicated by the fact that NOXA (MCL-1-specific antagonist; normal concentration, 10 to $100 \mu \mathrm{M}$ ) and HRK (BCL-X $\mathrm{L}^{-}$ specific antagonist; normal concentration, 10 to $100 \mu \mathrm{M}$ ) each caused robust depolarization, whereas $\mathrm{BAD}\left(\mathrm{BCL}-2 / \mathrm{BCL}-\mathrm{X}_{\mathrm{L}}-\right.$ specific antagonist; normal concentration, 10 to $100 \mu \mathrm{M})$ resulted in depolarization equal to HRK (Fig. 4A). Given that PIK3CA mutant breast cancers are dually dependent on MCL-1 and BCL- $\mathrm{X}_{\mathrm{L}}$ and that PI3K/mTOR inhibition sensitizes these cells to BCL- $\mathrm{X}_{\mathrm{L}}$ inhibition, we assessed whether $\mathrm{PI} 3 \mathrm{~K} / \mathrm{mTOR}$ inhibition may function through regulation of MCL1 expression and/or activity. Previous reports have suggested that $\mathrm{PI} 3 \mathrm{~K} / \mathrm{mTOR}$ inhibition can modulate MCL-1 protein amounts in certain cellular contexts (23-26). Immunoblotting of extracts derived from cells treated with DMSO control, single-agent BEZ235 or WEHI-539, or the combination of both drugs revealed that PI3K/ mTOR inhibition resulted in the loss of MCL-1 protein expression in the PIK3CA mutant, but not PIK3CA WT cells, whereas the amounts of BCL- $\mathrm{X}_{\mathrm{L}}$, BCL-2, BIM, BID, and other BCL-2 family proteins were unchanged (Fig. 4B and fig. S3A). Furthermore, in PIK3CA mutant BC cell lines, knockdown of MCL-1 with three independent 

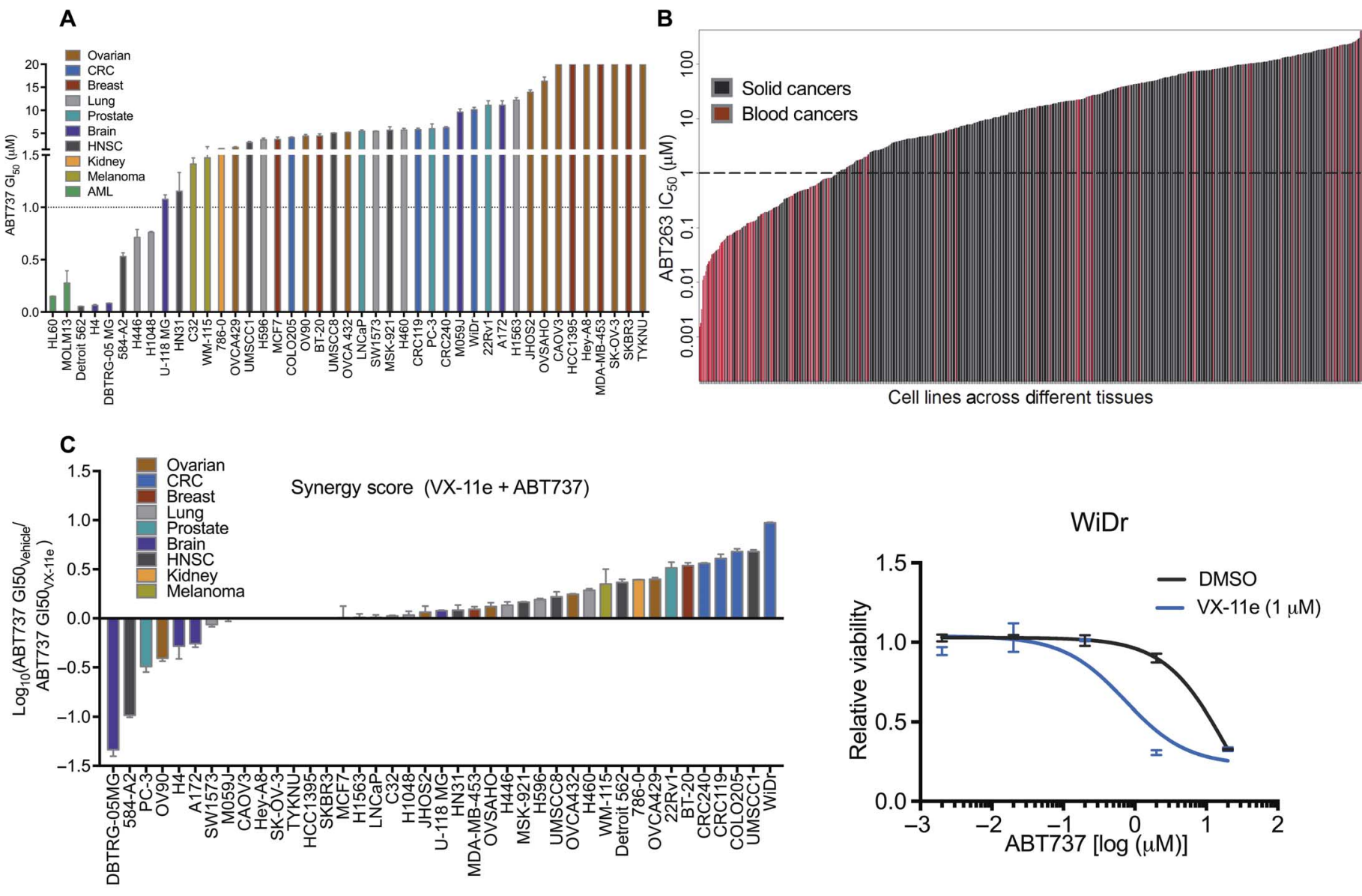

Cell lines across different tissues

D
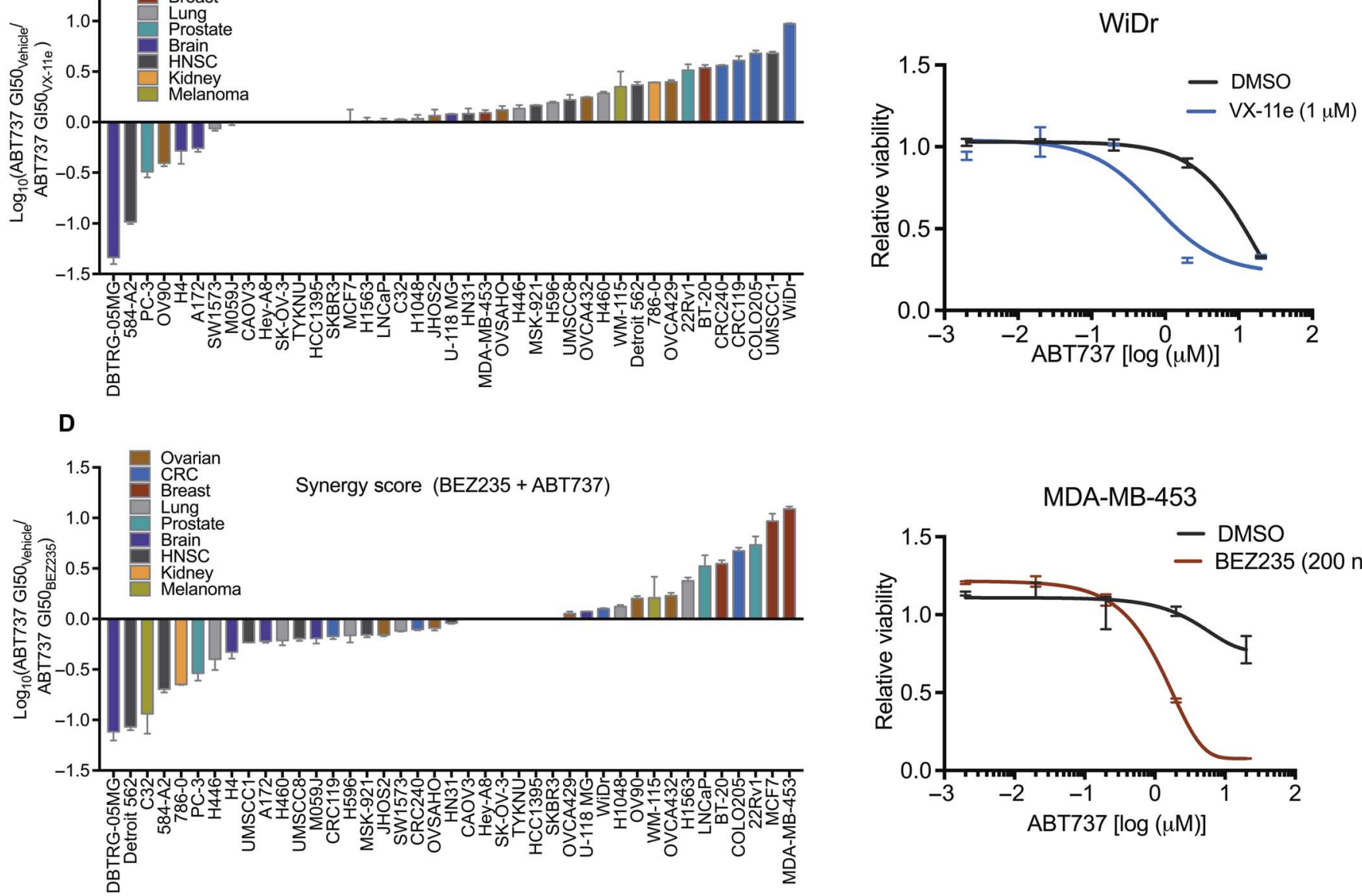

Fig. 1. Inhibition of the MAPK and PI3K pathways can sensitize solid tumors to BH3 mimetics in certain tissues. (A and $B$ ) Solid tumors are insensitive to single-agent $B H 3$ mimetics; dashed line indicates a sensitivity threshold of $1 \mu \mathrm{M}$ that was defined on the basis of the evidence that complete BCL-2/BCL- $X_{L}$ inhibition is achieved at this dose (20). (A) Short-term (3-day) growth inhibition ( $G I_{50}$ ) assay testing 43 cancer cell lines from 10 different tissue types using a dual BCL-2/BCL- $\mathrm{X}_{\mathrm{L}}$ inhibitor, ABT737. (B) CCLE data of 660 cancer cell lines treated in a $\mathrm{GI}_{50}$ assay with a dual BCL-2/BCL- $\mathrm{X}_{\mathrm{L}}$ inhibitor, $\mathrm{ABT} 263$. Black bars represent solid tumor lines, and red bars represent blood cancers. (C) Synergy score between $A B T 737$ and VX-11e, an ERK inhibitor, in the cell line panel from (A). Synergy score is defined as the ratio of the $A B T 737 \mathrm{Gl}_{50}$ value in the absence of VX-11e to the same value in the presence of $\mathrm{VX}-11 \mathrm{e}$. Additive effects result in a synergy score of zero, whereas synergistic and antagonistic effects yield scores greater than or less than zero, respectively. The $\mathrm{Gl} 50$ graph to the right features the top scoring cell line (WiDr) treated with ABT737 in the presence or absence of VX-11e. (D) Synergy score between ABT737 and BEZ235, a PI3K/mTOR inhibitor, in the cell line panel from (A). The $\mathrm{Gl}_{50}$ graph to the right features the top scoring cell line (MDA-MB-453) treated with ABT737 in the presence or absence of BEZ235. For experiments in all panels [except (B)], data are $n=3$. 
shRNAs phenocopied treatment with BEZ235 in growth and apoptosis assays (Fig. 4, C and D, and fig. S3, B and C). Although we were unable to stably express human or mouse MCL-1 protein in the presence of BEZ235 treatment, we reasoned that if MCL-1 and BCL- $\mathrm{X}_{\mathrm{L}}$ are the most important BCL-2 family antiapoptotic proteins, it should be possible to shift dependency from MCL-1 to BCL- $\mathrm{X}_{\mathrm{L}}$, and vice versa, using pharmacological and genetic approaches. Consistent with this hypothesis, treatment with BEZ235 shifted the dependency of cells to $\mathrm{BCL}-\mathrm{X}_{\mathrm{L}}$ in the $\mathrm{BH} 3$ profiling assay, phenocopying the effects of MCL-1 knockdown (Fig. 4, E and F, and fig. S3, C and D). Furthermore, BCL- $\mathrm{X}_{\mathrm{L}}$ knockdown shifted the dependency of cells to MCL1 (Fig. 4G and fig. S3, E and F). Finally, $\mathrm{GI}_{50}$ and apoptosis assays revealed that both treatment with BEZ235 and genetic inhibition of MCL-1 could be phenocopied using a selective small-molecule inhibitor of MCL-1, A-1210477 (Fig. 4, H and I, and fig. S3G) (27). Together, these data demonstrate that PI3K/mTOR inhibition cooperates with

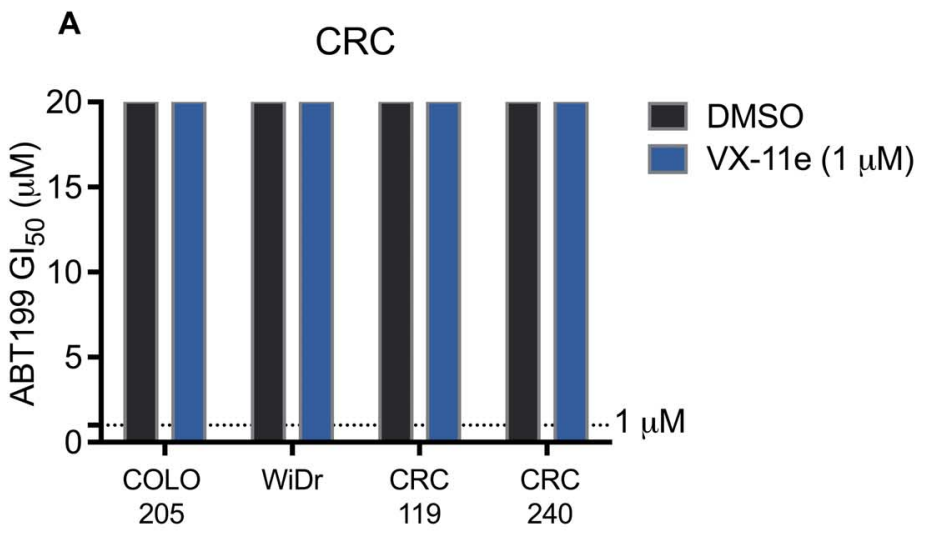

B
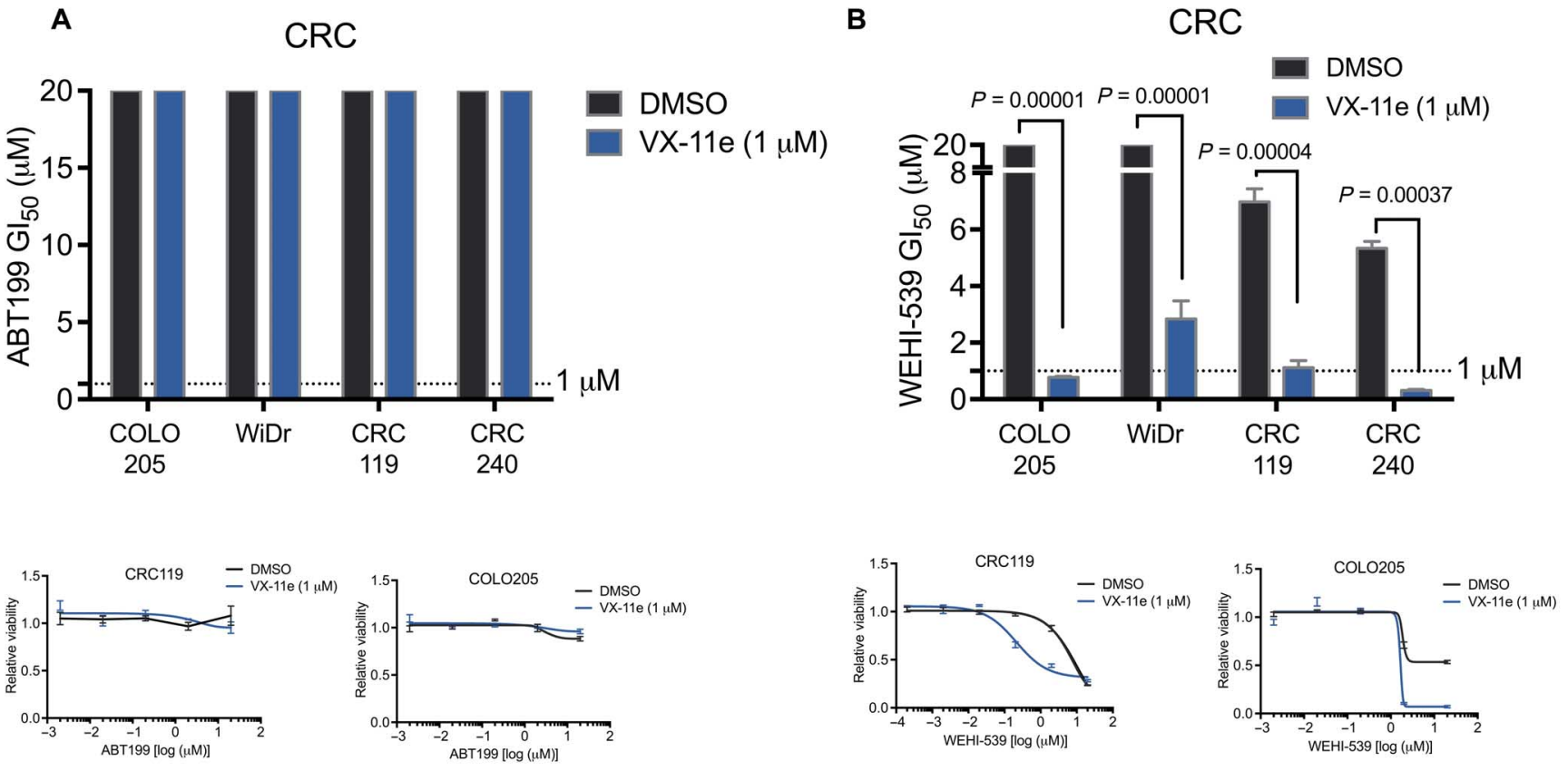

C

Breast
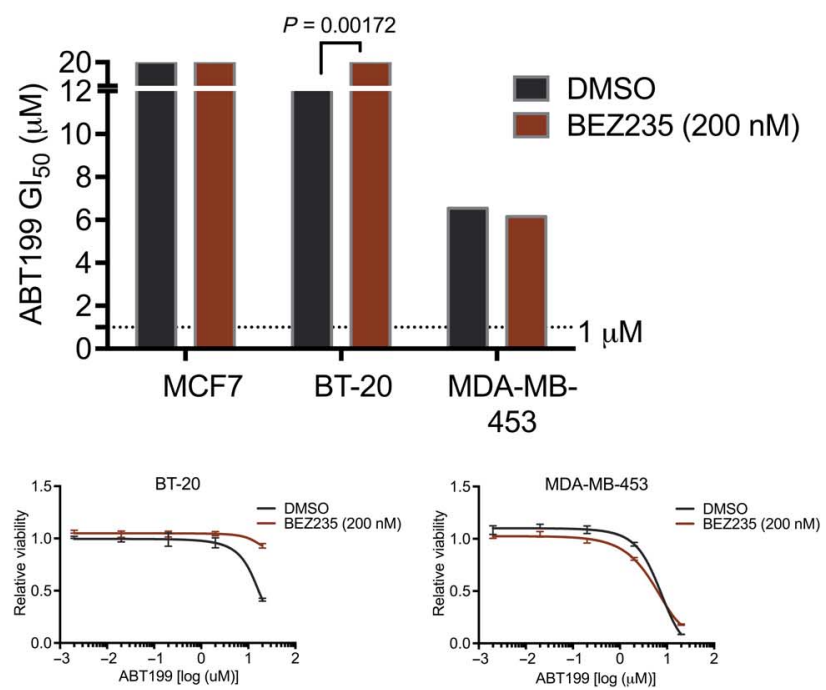

D
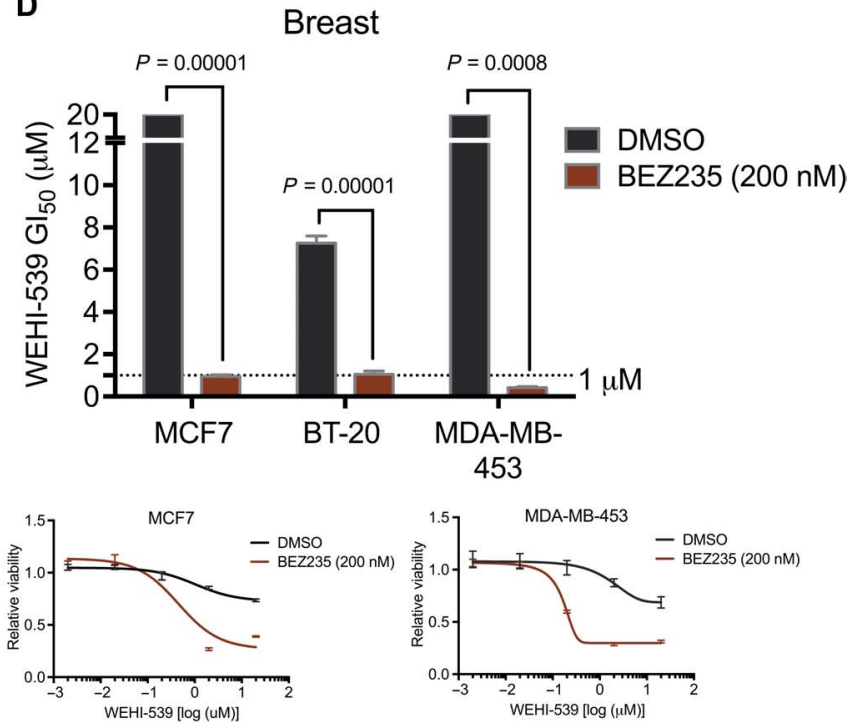

Fig. 2. $B C L-X_{L}$ is the relevant target of $A B T 737$ in $C R C$ and breast cancer. (A and $B$ ) The contributions of $B C L-2$ and $B C L-X_{L}$ to efficacy in $C R C$ cells. (A) $G I_{50}$ value of a selective $B C L-2$ inhibitor, $A B T 199$, in four CRC cell lines treated with either vehicle (DMSO) or an ERK inhibitor (VX-11e). (B) $\mathrm{Gl}_{50}$ value of a selective $B C L-X_{L}$ inhibitor, WEHI-539, in four CRC cell lines treated with either vehicle (DMSO) or an ERK inhibitor (VX-11e). Gl ${ }_{50}$ graphs below (A) and (B) are representative cell lines (CRC119 and COLO205) showing the Gl 50 shifts, or lack thereof, with combination treatment. (C and D) The contributions of BCL-2 and BCL-X to efficacy in breast cancer cells. (C) $\mathrm{Gl}_{50}$ value of a selective BCL-2 inhibitor, $A B T 199$, in three breast cancer cell lines treated with either vehicle (DMSO) or a PI3K/mTOR inhibitor (BEZ235). (D) $\mathrm{Gl}_{50}$ value of a selective BCL- $\mathrm{X}_{\mathrm{L}}$ inhibitor, WEHI-539, in three breast cancer cell lines treated with either vehicle (DMSO) or a PI3K/mTOR inhibitor (BEZ235). Gl 50 graphs below are representative cell lines (BT-20, MDA-MB-453, and MCF7) showing the Gl 50 shifts, or lack thereof, with combination treatment. For all panels, error bars show data \pm SEM. For experiments in all panels, data are $n=3$. 
A

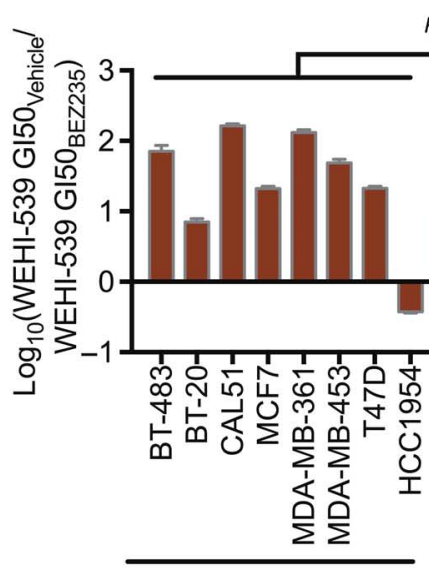

PIK3CA mutant

MDA-MB-361

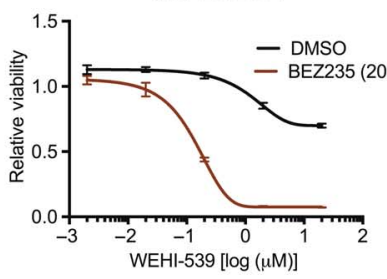

MCF7
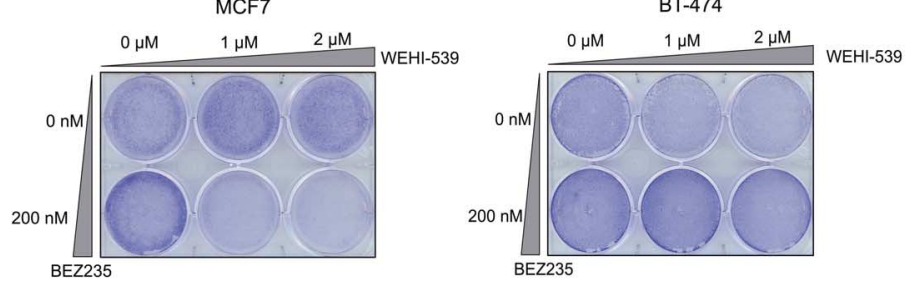

D

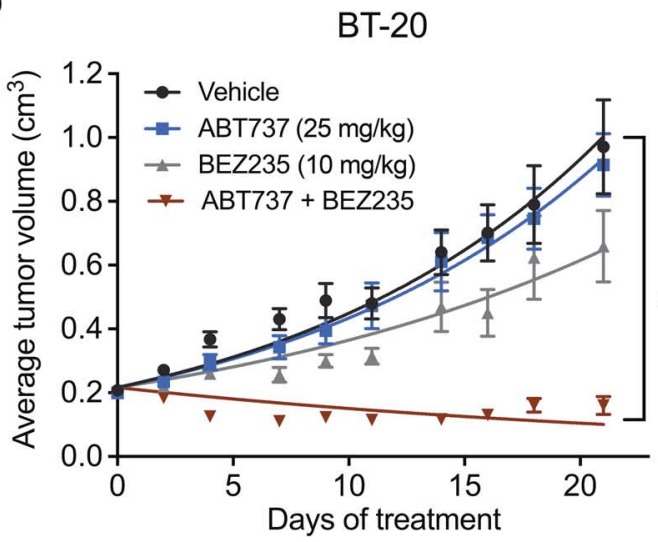

B

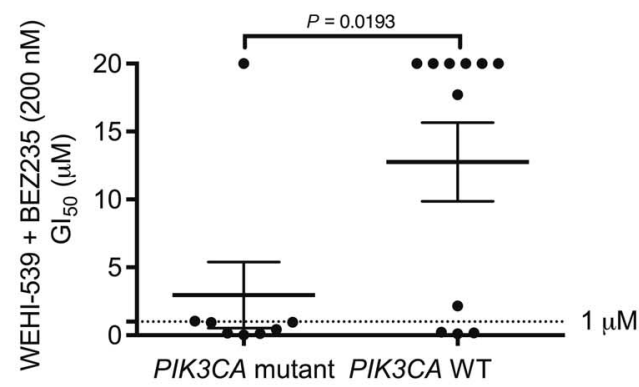

C

BT-20

SKBR3

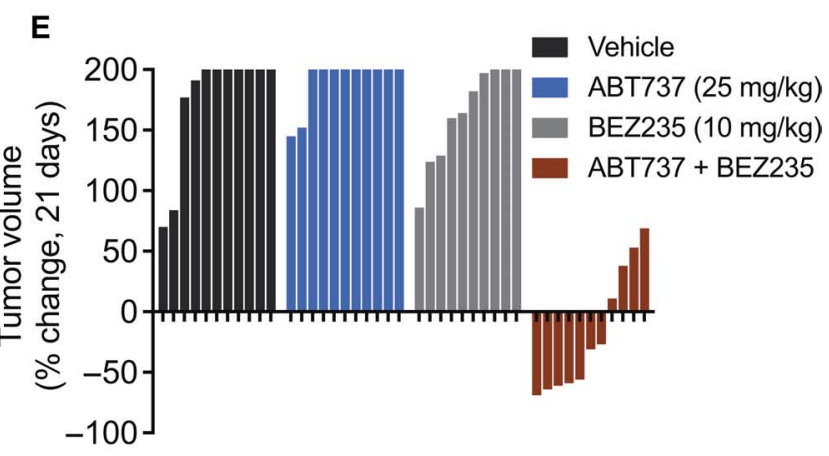

Fig. 3. Breast cancer cell lines with PIK3CA mutations respond to combined inhibition of PI3K/mTOR and BCL-X $\mathbf{X}_{\mathbf{L}}$. (A) Synergy score between WEHI-539 (BCL- $\mathrm{X}_{\mathrm{L}}$ inhibitor) and BEZ235 (PI3K/mTOR inhibitor) in a panel of breast cancer cell lines segregated by PIK3CA mutational status. Synergy score is defined as the ratio of the WEHI- $539 \mathrm{Gl}_{50}$ value in the absence of BEZ235 to the same value in the presence of BEZ235. Additive effects result in a synergy score of zero, whereas synergistic effects and antagonistic effects yield scores greater than or less than zero, respectively. The $\mathrm{Gl}_{50}$ graphs below are representative cell lines (MDA-MB-361 and AU565). The images below the graphs are two-dimensional (2D) growth assays in two representative cell lines (MCF7 and BT-474) treated with a BCL- $\mathrm{K}_{\mathrm{L}}$ inhibitor (WEHI-539) in combination with a PI3K/mTOR inhibitor (BEZ235). (B) $\mathrm{Gl}_{50}$ value of cell lines treated with a BCL-X inhibitor, WEHI-539, in the presence of a PI3K/mTOR inhibitor, BEZ235, stratified by PIK3CA mutation status. (C) Apoptosis measurements for BCL- $\mathrm{X}_{\mathrm{L}}$ and PI3K/mTOR dual inhibition reported as the percentage of cells that were annexin $\mathrm{V}^{+}$after a 48-hour drug treatment. BT-20 and SKBR3 are representative PIK3CA mutant and WT cell lines, respectively. (D) BT-20 orthotopic xenografts treated with vehicle, ABT737, BEZ235, or the combination for 21 days, shown as tumor size versus time. $n=11$ for all arms except BEZ235 where $n=10$. Data were analyzed using two-way analysis of variance (ANOVA) of matched values followed by Bonferroni multiple comparisons test to establish significance $(P<0.05)$ of the difference between groups at each day of treatment. (E) Waterfall plot for BT-20 orthotopic xenografts calculated as percentage change in tumor volume as compared to tumor size at the initiation of treatment. For all panels, error bars show data \pm SEM. For experiments in all panels [except (D) and (E)], data are $n=3$. 


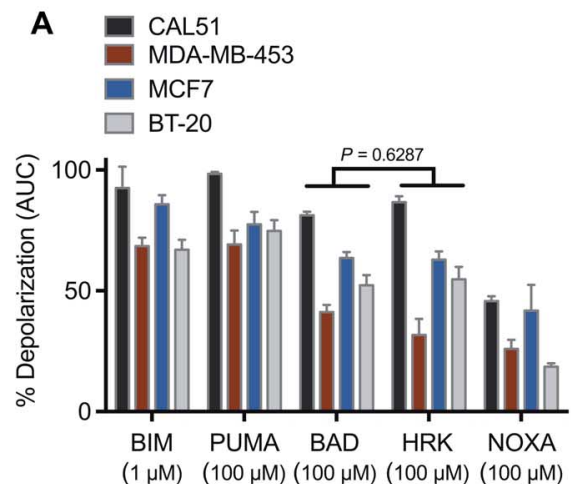

C

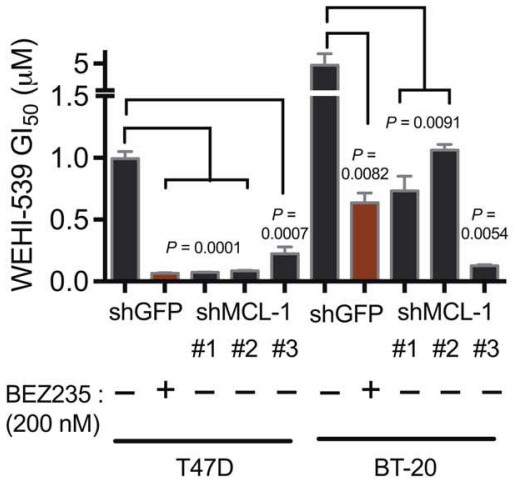

B

$\underline{\text { CAL51 }}$

MDA-MB-453

AU565

MDA-MB-436

KEY:

1: DMSO

2: BEZ235

(200 nM)

3: WEHI-539

$(2 \mu \mathrm{M})$

4: Combo

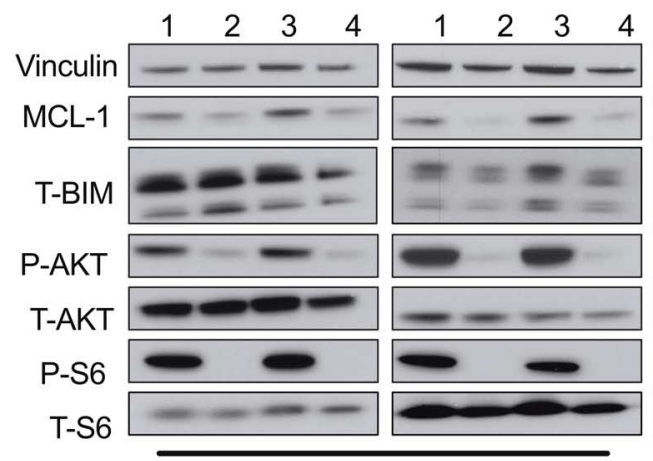

PIK3CA mutant
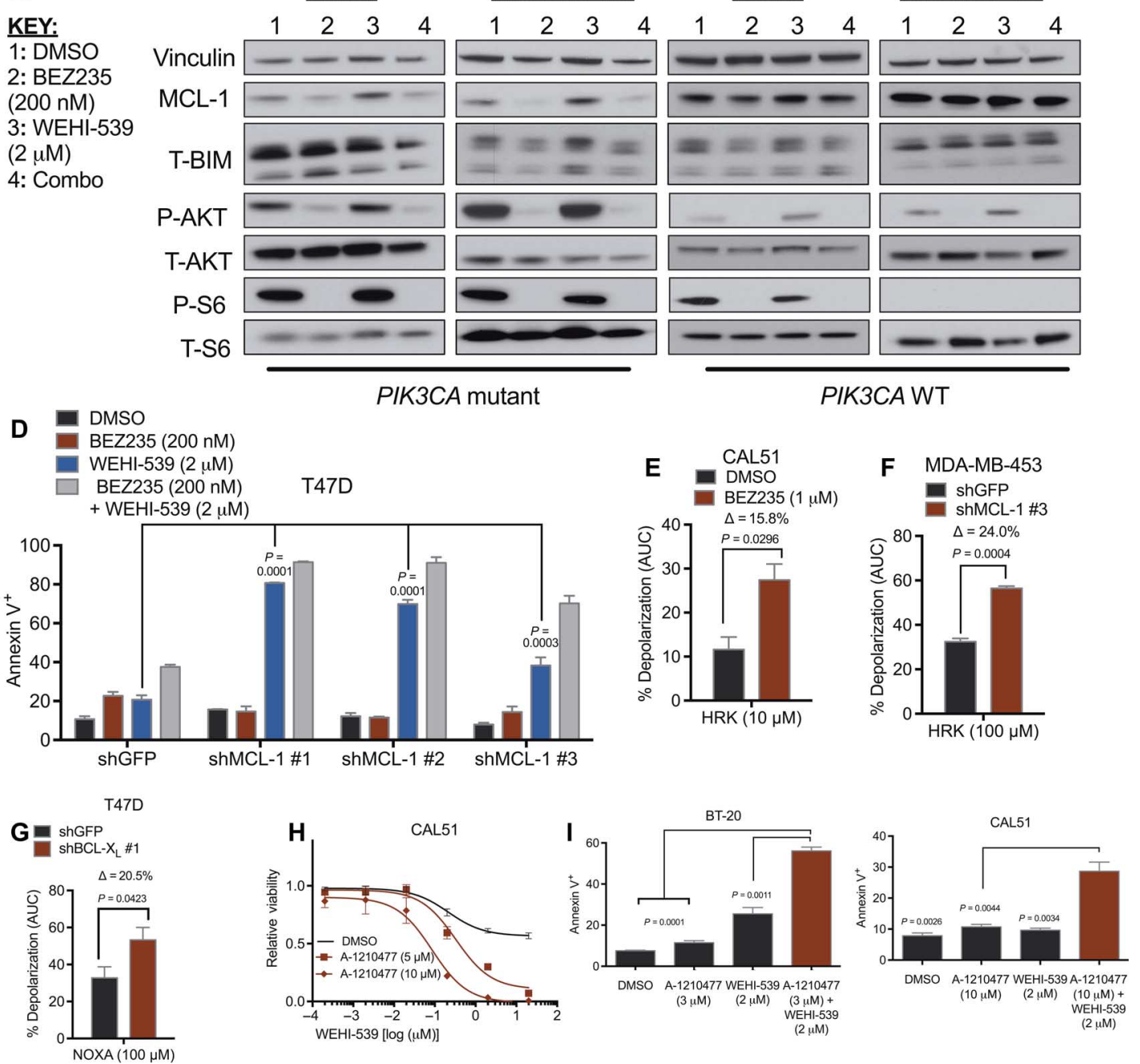

Fig. 4. PIK3CA mutant breast cancers depend on $B C L-X_{L}$ and $M C L-1$ for survival. (A) BH3 profiling of five PIK3CA mutant breast cancer cell lines. AUC, area under the curve. (B) Immunoblot of PIK3CA mutant and WT cell lines treated with vehicle (DMSO), single-agent PI3K/mTOR inhibitor (BEZ235), single-agent BCL- $\mathrm{X}_{\mathrm{L}}$ inhibitor (WEHI-539), or the combination. CAL51, MDA-MB-453, AU565, and MDA-MB-436 are representative cell lines. P-AKT is at the S473 site and P-S6 is at the S235/236 site. The loading control is vinculin for all cell lines. Doses are indicated in the key. Images are cropped for clarity. (C) $\mathrm{Gl}_{50}$ value of a $B C L-\mathrm{X}_{\mathrm{L}}$ inhibitor, WEHI-539, in cells with or without PI3K/mTOR inhibitor (BEZ235) or cells with MCL-1 knockdown without the PI3K/mTOR inhibitor. T47D and BT-20 are representative PIK3CA mutant cell lines. GFP, green fluorescent protein. (D) Apoptosis measurements in control cells or MCL-1 knockdown cells treated with vehicle (DMSO), single-agent inhibitor PI3K/mTOR inhibitor (BEZ235), single-agent BCL- $\mathrm{X}_{\mathrm{L}}$ inhibitor (WEHI-539), or the combination. T47D is a representative cell line. (E) BH3 profiling in a cell line treated with a PI3K/ mTOR inhibitor (BEZ235). (F) BH3 profiling in a cell line with MCL-1 knockdown. (G) BH3 profiling in a cell line with $B C L-X_{L}$ knockdown. (H) Gl $I_{50}$ Curve in a PIK3CA mutant cell line treated with a BCL- $\mathrm{X}_{\mathrm{L}}$ inhibitor (WEHI-539) and either vehicle (DMSO) or an MCL-1 inhibitor (A-1210477). CAL51 is a representative cell line. (I) Apoptosis measurements in PIK3CA mutant cell lines treated with vehicle (DMSO), an MCL-1 inhibitor (A-1210477), a BCL- $\mathrm{K}_{\mathrm{L}}$ inhibitor (WEHI-539), or the combination. BT-20 and CAL51 are representative cell lines. For all panels (excluding immunoblots), error bars show data \pm SEM. For all experiments, data are $n=3$. 
BCL- $\mathrm{X}_{\mathrm{L}}$ inhibition in PIK3CA mutant breast cancer cells through its suppression of MCL-1 protein expression.

\section{MCL-1 translation is controlled by the mTOR/4E-BP axis in PIK3CA mutant tumors}

To define the mechanism by which PI3K/mTOR inhibition suppresses MCL-1, we first established that MCL-1 is regulated by the PI3K/mTOR pathway at the level of protein translation because neither MCL1 transcription nor protein stability was affected by BEZ235 treatment. This observation is consistent with the well-established role of this pathway in translational regulation (fig. S4, A and B) (28). Next, to distinguish the contributions of PI3K versus mTOR to MCL-1 regulation, we treated three PIK3CA mutant breast cancer cell lines with a panel of PI3K/mTOR pathway inhibitors (BEZ235, BKM-120, BYL-719, rapamycin, Torin1, AZD2014, and MLN-0128), each in combination with WEHI-539 (BCL- $\mathrm{X}_{\mathrm{L}}$ inhibitor). Whereas the pan- and p110 $\alpha$-selective PI3K inhibitors BKM-120 and BYL-719, respectively, were unable to consistently sensitize cells to WEHI-539, the adenosine $5^{\prime}$-triphosphate (ATP)-competitive mTORC1/2 inhibitors Torin1, MLN-0128, and AZD2014 fully phenocopied the effects of BEZ235, and the allosteric partial mTORC1 inhibitor rapamycin exerted variable effects across cell lines (Fig. 5A). These findings are reminiscent of studies establishing that ATPcompetitive mTORC1/2 inhibitors robustly suppress cap-dependent translation through 4E-BP protein dephosphorylation downstream of mTORC1, whereas rapamycin's effects on this axis are variable (29). Given that MCL-1 is translated in a cap-dependent manner, as evidenced by the fact that pharmacological disruption of the eIF4F complex with the small-molecule inhibitor 4EGI-1 suppressed MCL-1 protein expression (Fig. 5B) and that cooperation with WEHI-539 was associated with suppression of 4E-BP1 phosphorylation by MLN-0128 (Fig. 5C), we hypothesized that mTOR inhibition blocks MCL-1 expression through $4 \mathrm{E}-\mathrm{BP}-$ mediated suppression of cap-dependent translation. Using the $\mathrm{m}^{7}$ GTP pull-down assay, we observed that mTOR inhibition disrupted eIF4F complex stability and cap-dependent translation through 4E-BP, as evidenced by the loss of association between eIF4E and eIF4G1 and an increase in association between eIF4E and 4E-BP1, after MLN-0128 treatment in PIK3CA mutant cells (Fig. 5D and fig. S4C).

Finally, given that BEZ235's clinical development has been halted because of poor pharmacokinetics and toxicity and that its activity in PIK3CA mutant cells can be phenocopied using ATP-competitive mTOR inhibitors like MLN-0128 and AZD2014 that are currently in clinical development for the treatment of breast cancer, ovarian cancer, glioblastoma multiforme, and other cancers (NCT02193633, NCT02208375, NCT02583542, NCT0271969, NCT02575339, and NCT02412722), we sought to validate the use of this class of agents in combination with BCL- $\mathrm{X}_{\mathrm{L}}$ inhibitors $(30,31)$. Like BEZ235, MLN-0128 was able to induce apoptosis in mutant cell lines (but not WT), suppress MCL-1 expression, and inhibit the growth of orthotopic, PIK3CA mutant TNBC xenografts when combined with BCL- $\mathrm{X}_{\mathrm{L}}$ inhibition (Fig. 5, E to G, fig. S4, D and $\mathrm{E}$, and table $\mathrm{S} 3$ ). We observed mild loss of weight in one mouse from the MLN-0128 arm of the study (1 day of missed dosing; see Materials and Methods for details) as well as two mice from the combinationtreated arm of the study (3 days of missed dosing each). However, most of the mice did not lose substantial weight over the course of the treatment (fig. S4F). Together, these results indicate that PI3K/mTOR inhibition cooperates with BCL- $\mathrm{X}_{\mathrm{L}}$ inhibition in PIK3CA mutant cells through $\mathrm{mTOR} / 4 \mathrm{E}-\mathrm{BP}$-mediated suppression of cap-dependent MCL-1 translation and that tumor growth suppression can be achieved using clinically viable $\mathrm{mTORC} 1 / 2$ inhibitors in vivo.

\section{PIK3CA WT breast cancers treated with direct MCL-1 and $B C L-X_{L}$ inhibitors undergo apoptosis}

Given the robustness of apoptosis induction in PIK3CA mutant cells treated with mTOR plus BCL- $\mathrm{X}_{\mathrm{L}}$ inhibitors, we sought to characterize the apoptosis regulation occurring in PIK3CA WT cell lines to understand why the combination was ineffective in this context. $\mathrm{BH} 3$ profiling results from PIK3CA WT cell lines were indistinguishable from those from PIK3CA mutant breast cancer cell lines. Like mutant lines, WT lines appeared to be primed for apoptosis and dually dependent on MCL-1 and BCL- $\mathrm{X}_{\mathrm{L}}$ (Fig. 6A). MCL1 knockdown in PIK3CA WT cell lines created a synthetic dependence on BCL- $\mathrm{X}_{\mathrm{L}}$ in growth and apoptosis assays, resulting in submicromolar potency of WEHI-539 (Fig. 6, B and C, and fig. S5, A to C). Furthermore, $\mathrm{BH} 3$ profiling in WT cell lines in the presence of MCL1 knockdown detected a shift toward BCL- $\mathrm{X}_{\mathrm{L}}$ dependency (Fig. 6D and fig. S5C), and reciprocally, BCL- $\mathrm{X}_{\mathrm{L}}$ knockdown shifted the dependency of cells to MCL-1 (Fig. 6E and fig. S5, D and E). Consistent with the hypothesis that PIK3CA WT breast cancers depend on both BCL- $\mathrm{X}_{\mathrm{L}}$ and MCL-1, treatment with selective inhibitors of both these targets, WEHI-539 and A-1210477, respectively, was highly effective in growth and apoptosis assays (Fig. 6, F and G, and fig. S5F). As predicted by $\mathrm{BH} 3$ profiling, $\mathrm{BCL}-2$ does not play an important prosurvival role in this context, as evidenced by the fact that BCL- $\mathrm{X}_{\mathrm{L}}$ plus MCL-1 inhibition did not appreciably affect the sensitivity of PIK3CA WT cell lines to ABT199, a selective BCL-2 inhibitor (fig. S5G). In a model of PIK3CA WT TNBC (MDA-MB-436), tumor growth inhibition was achieved after combined inhibition of MCL-1 (using CRISPR/Cas9-mediated knockout, necessitated by the current unavailability of a direct, bioavailable small-molecule inhibitor of MCL-1) and BCL- $\mathrm{X}_{\mathrm{L}}$ (using ABT737), whereas each treatment alone had no effect (Fig. 6H and tables S3 and S4). Collectively, these results reveal that, like PIK3CA mutant breast cancers, PIK3CA WT cancers are primed for apoptosis and exhibit a dual dependence on MCL-1 and BCL- $\mathrm{X}_{\mathrm{L}}$, the inhibition of which induces apoptosis.

Given these results, we hypothesized that the lack of efficacy between mTOR and BCL- $\mathrm{X}_{\mathrm{L}}$ inhibitors in PIK3CA WT cells may be based on the fact that mTOR can only modulate MCL-1 expression in the PIK3CA mutant context, a notion supported by our finding that MCL-1 expression is stable after mTOR inhibition in WT lines (Fig. 4B). To understand why mTOR inhibition fails to suppress MCL-1 expression in this context, we began by verifying that MLN-0128 treatment results in a loss of $4 \mathrm{E}-\mathrm{BP} 1$ phosphorylation in these cells, consistent with our findings in PIK3CA mutant cells (Fig. 6I). Given this, alongside the fact that MCL-1 is translated in a cap-dependent manner in WT cells (Fig. 6J), we reasoned that mTOR inhibition may simply fail to disrupt eIF4F complex activity in these cells despite its regulation of $4 \mathrm{E}-\mathrm{BP}$ phosphorylation. $\mathrm{m}^{7} \mathrm{GTP}$ pull-down assays revealed that MLN-0128 treatment was unable to disrupt eIF4F complex activity, as indicated by the relatively stable association of eIF4E and eIF4GI and by the diminished drug-induced association of eIF4E with 4E-BP1, in PIK3CA WT cell lines relative to PIK3CA mutant cell lines (Fig. 6K and fig. $\mathrm{S} 5 \mathrm{H}$ ). Consistent with previous studies demonstrating multiple levels of eIF4F regulation, these results demonstrate that capdependent MCL-1 translation is rate-limited by $\mathrm{mTOR} / 4 \mathrm{E}-\mathrm{BP}$ activity in PIK3CA mutant cells, but that in WT cells, it is limited by other aspects of eIF4F complex regulation, suggesting that future studies to elucidate these mechanisms may yield indirect strategies to target MCL-1 in these tumors $(32,33)$. 
A $\begin{array}{ll} & \text { DMSO } \\ \text { BEZ235 (200 nM) } & \square \text { Rapamycin (100 nM) } \\ \text { BKM-120 (1 } \mu \mathrm{M}) & \square \text { AZDin1 (200 nM) } \\ \text { BYL-719 (500 nM) } & \square \text { MLN-0128 (200 nM) }\end{array}$

T47D

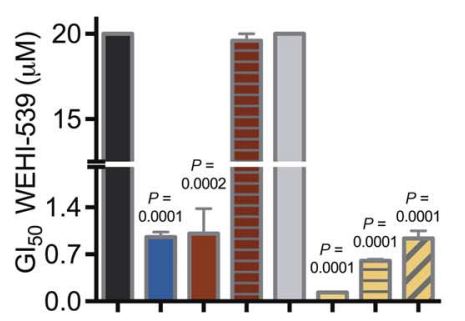

B
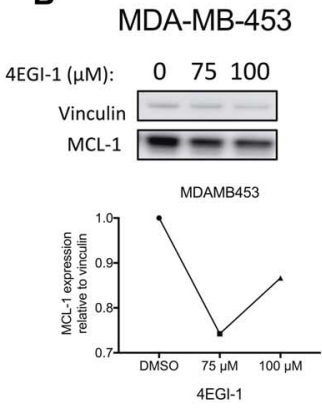

C (2:1:

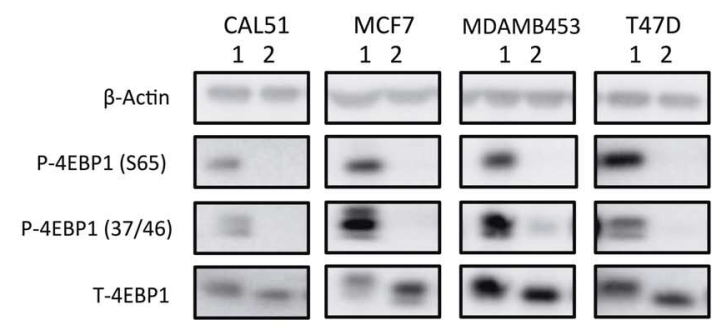

1: DMSO

2: $\mathrm{MLN}-0128(200 \mathrm{nM})$
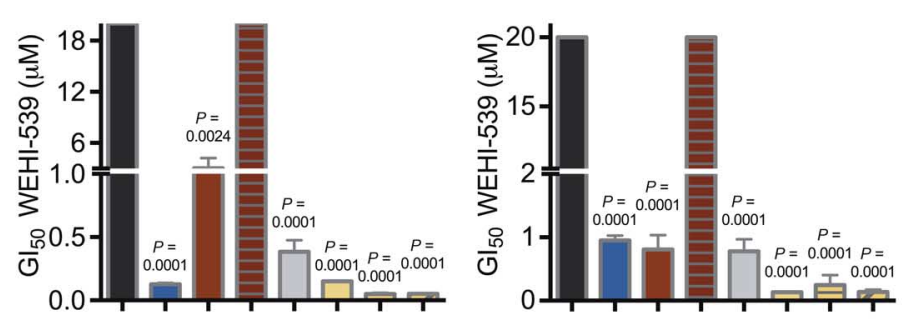

D

MLN-0128

(200 nM)

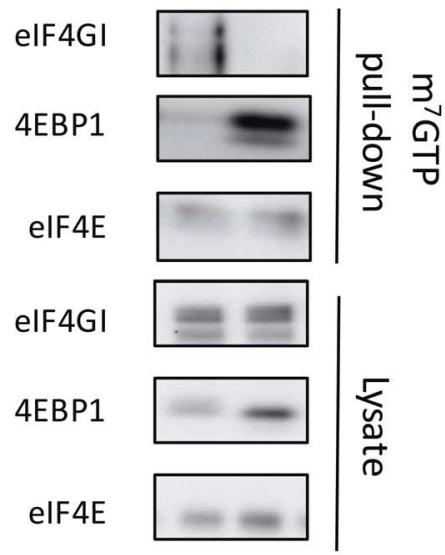

G

$\mathrm{MLN}-0128=200 \mathrm{nM}$

AZD2014 $=200 \mathrm{nM}$

WEHI-539 $=2 \mu \mathrm{M}$

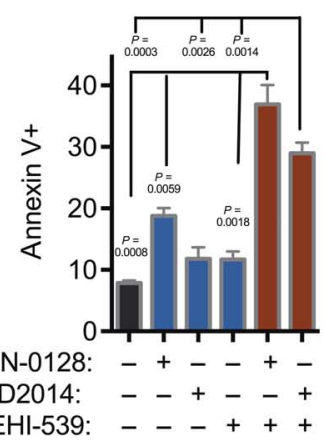

MDA-MB-453

$\mathbf{F}$

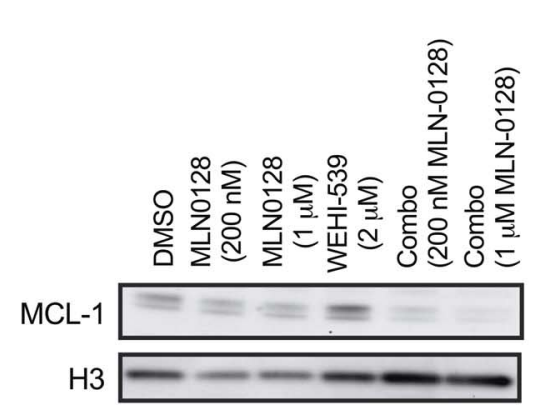

BT-20

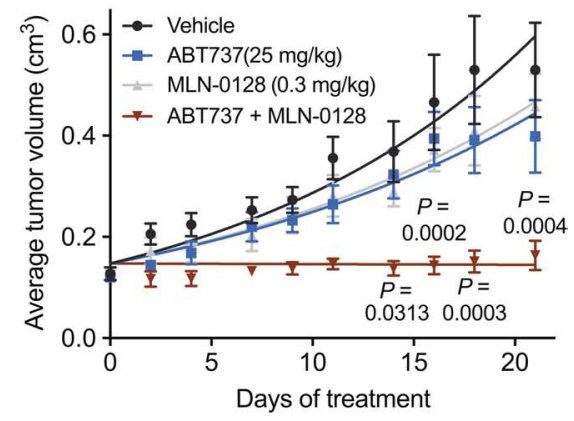

Fig. 5. MCL-1 translation is controlled by the mTOR/4E-BP axis in PIK3CA mutant tumors. (A) $\mathrm{Gl}_{50}$ value of a selective BCL-X inhibitor, WEHI-539, in three breast cancer cell lines treated with either vehicle (DMSO), a dual PI3K/ mTOR inhibitor (BEZ235), a pan-PI3K inhibitor (BKM-120), a p110 $\alpha$ isoform-specific PI3K inhibitor (BYL-719), a partial allosteric mTORC1 inhibitor (rapamycin), and three mTORC1/2 inhibitors (Torin1, AZD2014, and MLN-0128). (B) Immunoblot of MCL-1 in a PIK3CA mutant cell line treated with DMSO or an inhibitor of cap-dependent translation, 4EGI-1. Images are cropped for clarity. (C) Immunoblot of P-4E-BP1 and total 4E-BP1 in four cell lines treated with vehicle or an mTORC1/2 inhibitor (MLN-0128). Images are cropped for clarity. (D) Immunoblot of 4EBP1, elF4E, and elF4GI in total cell lysates or $\mathrm{m}^{7} \mathrm{GTP}$ pull-down in a PIK3CA mutant cell line treated with vehicle (DMSO) or an mTORC1/2 inhibitor (MLN-0128). Images are cropped for clarity. (E) Apoptosis measurements in a PIK3CA mutant cell line treated with vehicle (DMSO), one of two mTORC1/2 inhibitors (MLN-0128 or AZD2014), a BCL-X inhibitor (WEHI-539), or the combination of WEHI-539 with either MLN-0128 or AZD2014. (F) Immunoblot of MCL-1 in a PIK3CA mutant cell line treated with vehicle, two doses of an mTORC1/2 inhibitor (MLN-0128), a BCL-X inhibitor (WEHI-539), or the combination of MLN-0128 and WEHI-539 (2 $\mu$ M). Images are cropped for clarity. (G) BT-20 orthotopic xenografts treated with vehicle $(n=7)$, ABT737 $(n=7)$, MLN-0128 $(n=9)$, or the combination $(n=8)$ for 21 days, shown as tumor size versus time. Data were analyzed using two-way ANOVA of matched values followed by Bonferroni multiple comparisons test to establish significance $(P<0.05)$ of the difference between groups at each day of treatment. For all panels (except immunoblots), error bars show data \pm SEM. For experiments in all panels [except $(G)$ ], data are $n=3$. 
A
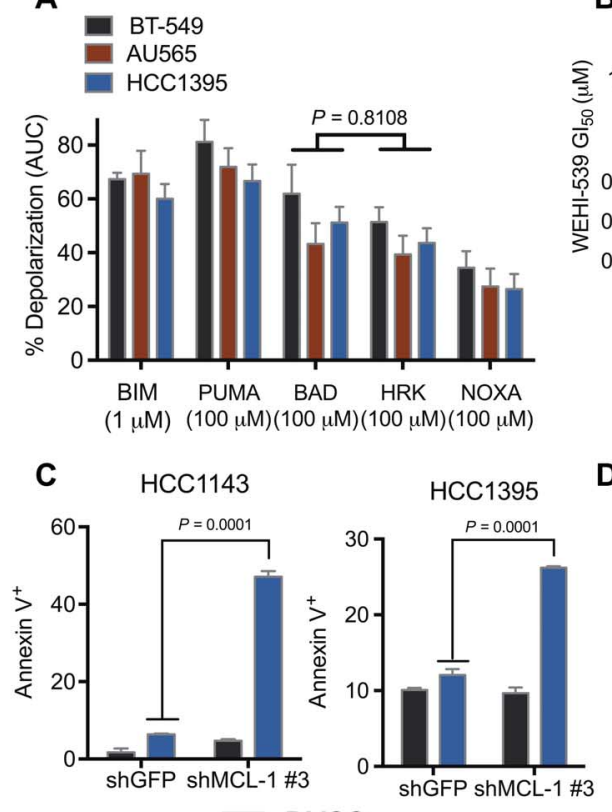

DMSO

WEHI-539(2 $\mu \mathrm{M})$
B

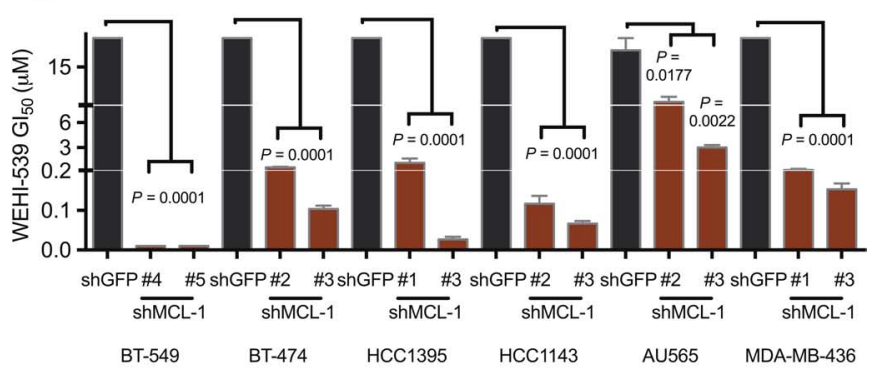

D

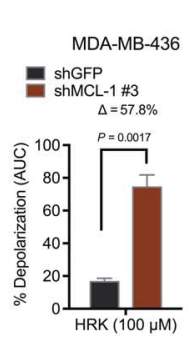

E

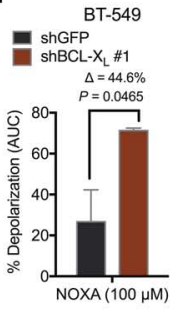

$\mathbf{F}$

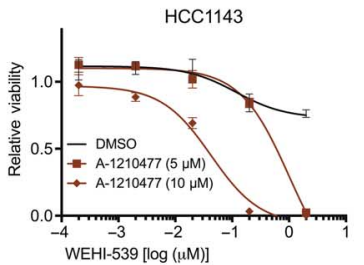

H
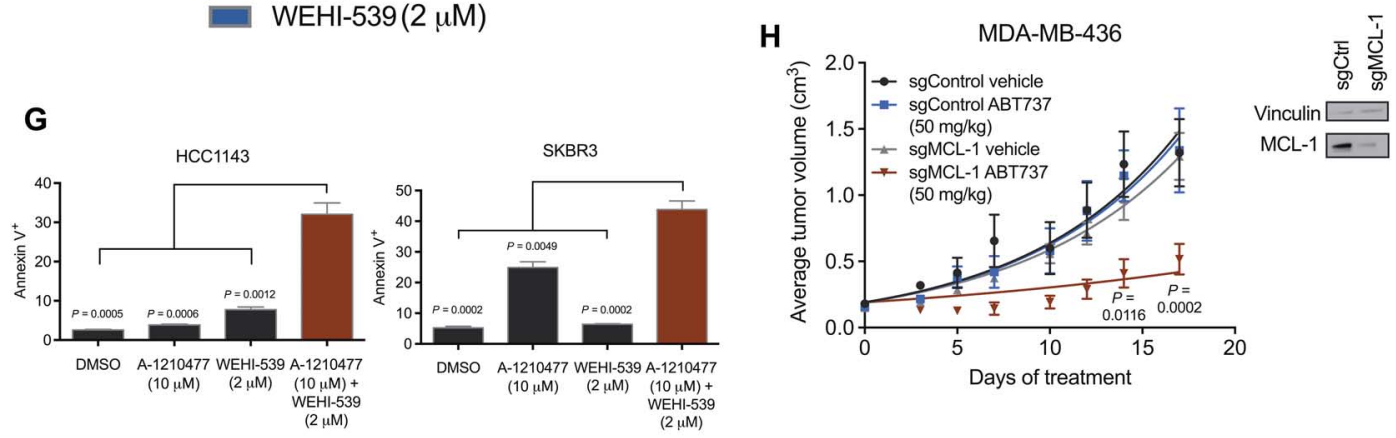

I

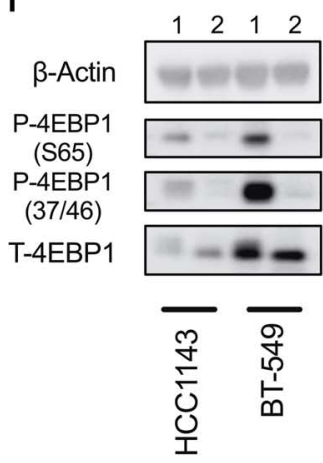

AU565

$$
\begin{aligned}
& \text { 1. DMSO } \\
& \text { 2. MLN-0128 } \\
& (200 \mathrm{nM})
\end{aligned}
$$

$J$

4EGI-1 ( $\mu \mathrm{M})$

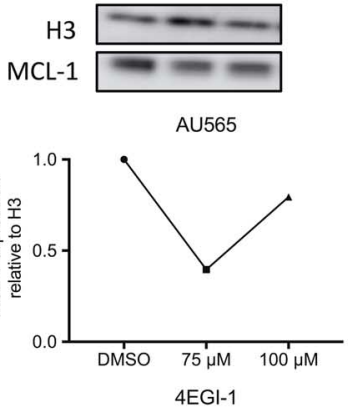

K

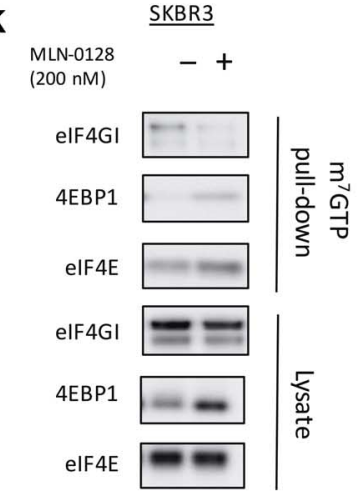

Fig. 6. PIK3CA WT breast cancers respond to a $B C L-X_{L}$ inhibitor in combination with a direct $M C L-1$ inhibitor. (A) $B H 3$ profiling of three breast cancer cell lines. (B) $\mathrm{Gl}_{50}$ value of a BCL-X inhibitor, WEHI-539, in control cells or cells with MCL-1 knockdown. (C) Apoptosis measurements by annexin V binding in control cells or MCL-1 knockdown cells treated with vehicle (DMSO) or single-agent BCL- $\mathrm{X}_{\mathrm{L}}$ inhibitor (WEHI-539). HCC1143 and HCC1395 are representative cell lines. (D) BH3 profiling in a cell line with MCL-1 knockdown. (E) BH3 profiling in a cell line with BCL- $\mathrm{K}_{\mathrm{L}}$ knockdown. $(\mathbf{F}) \mathrm{Gl}_{50}$ curves in a PIK3CA WT cell line treated with a BCL-X $\mathrm{L}_{\mathrm{L}}$ inhibitor (WEHI-539) and either vehicle (DMSO) or an MCL-1 inhibitor (A-1210477). $\mathrm{HCC} 1143$ is a representative cell line. (G) Apoptosis measurements in PIK3CA WT cell lines treated with vehicle (DMSO), an MCL-1 inhibitor (A-1210477), a BCL-X inhibitor (WEHI-539), or the combination. HCC1143 and SKBR3 are representative cell lines. For (A) to (G), error bars show data \pm SEM. For experiments in (A) to (G), data are $n=3$. (H) MDA-MB436 orthotopic xenografts stably expressing Cas9 along with either sgCtrl or sgMCL-1 and treated with vehicle (sgCtrl, $n=6 ;$ sgMCL-1, $n=7$ ) or ABT737 (sgCtrl, $n=5 ;$ sgMCL$1, n=6)$ for 21 days, shown as tumor size versus time. Data were analyzed using two-way ANOVA of matched values followed by Bonferroni multiple comparisons to establish significance $(P<0.05)$ of the difference between groups at each day of treatment. To the right is an immunoblot confirming MCL-1 knockdown in the sgMCL1 cells before the start of the xenograft experiment. Images are cropped for clarity. (I) Immunoblot of P-4E-BP1 (S65) and total 4E-BP1 in two cell lines treated with vehicle or an mTORC1/2 inhibitor (MLN-0128). Images are cropped for clarity. (J) Immunoblot of MCL-1 in a PIK3CA WT cell line treated with DMSO or an inhibitor of cap-dependent translation, 4EGI-1. Images are cropped for clarity. (K) Immunoblot of 4EBP1, elF4E, or elF4GI in total cell lysates or $\mathrm{m}^{7} \mathrm{GTP}$ pull-down in a PIK3CA WT cell line treated with vehicle (DMSO) or an mTORC1/2 inhibitor (MLN-0128). Images are cropped for clarity. 
Additional considerations guide the potential clinical translation of combined $\mathrm{mTORC} 1 / 2$ and $\mathrm{BCL}-\mathrm{X}_{\mathrm{L}}$ inhibition

We sought to investigate three additional areas of relevance to the clinical translation of therapies targeting the BCL- $\mathrm{X}_{\mathrm{L}}$ and $\mathrm{mTOR} / \mathrm{MCL}-1$ axes: (i) the dependence of primary human breast tumors on BCL- $\mathrm{X}_{\mathrm{L}}$ and MCL-1; (ii) the potential of mTORC1/2 inhibition to exacerbate on-target thrombocytopenia secondary to BCL- $\mathrm{X}_{\mathrm{L}}$ inhibition (10); and (iii) the potential to combine mTOR/MCL-1 plus BCL- $\mathrm{X}_{\mathrm{L}}$ targeting with standard-of-care chemotherapies. In the first area, we used conditional reprogramming to briefly expand human patient-derived breast tumor cells obtained with surgical resection to provide sufficient numbers of cells for analysis and then subjected these cultures to $\mathrm{BH} 3$ profiling (table S5) (34). Like established breast cancer cell lines, primary tumors were highly primed for apoptosis and specifically dependent on MCL1 and BCL-X $\mathrm{X}_{\mathrm{L}}$ (Fig. 7A and fig. S6A). In contrast, normal breast epithelial cells obtained from reduction mammoplasty and immortalized using the human telomerase catalytic subunit, with (p53-inactive) or without (p53-active) the SV40 early region (HMLE and HME, respectively), were substantially less primed for apoptosis and dependent on BCL-2 instead of BCL- $\mathrm{X}_{\mathrm{L}}$ and MCL-1, as evidenced by their sensitivity to the BAD peptide and insensitivity to the HRK peptide (Fig. 7B) (35). This result is consistent with a growing body of evidence suggesting that most normal cells in adults lack apoptotic priming and suggests that normal epithelial cells should be insensitive to combined BCL- $\mathrm{X}_{\mathrm{L}}$ and $\mathrm{PI} 3 \mathrm{~K} / \mathrm{mTOR}$ inhibition, a hypothesis we verified experimentally using $\mathrm{GI}_{50}$ and apoptosis assays (Fig. $7, \mathrm{C}$ and D) $(6,36)$. In the second area, to address the possibility that mTOR inhibition may potentiate thrombocytopenia resulting from $B C L-\mathrm{X}_{\mathrm{L}}$ inhibition, we isolated platelets from two human donors and treated them with a BCL- $\mathrm{X}_{\mathrm{L}}$ inhibitor (WEHI-539) in the presence of vehicle (DMSO), BEZ235, or MLN-0128. We found that none of these combinations increased platelet sensitivity to BCL- $\mathrm{X}_{\mathrm{L}}$ inhibition, a result that is in contrast with the marked sensitization of PIK3CA mutant breast cancer cells treated with this combination (Fig. $7 \mathrm{E})$. In the third area, given that combined BCL- $\mathrm{X}_{\mathrm{L}}$ and MCL-1 inhibition shifts the balance of pro- to antiapoptotic signals in the mitochondria, we reasoned that these combinations may also sensitize breast cancer cells to standard-of-care chemotherapies that exploit apoptosis as part of their mechanisms of action. Direct inhibition of MCL-1 and BCL- $\mathrm{X}_{\mathrm{L}}$ was effective when combined with the anthracycline DNA-intercalating agent doxorubicin and the topoisomerase inhibitor etoposide in both PIK3CA mutant and WT TNBC cell lines in $\mathrm{GI}_{50}$ and apoptosis assays (Fig. 7, F and G, and fig. S6B). Similarly, indirect inhibition of MCL-1 using BEZ235 in combination with a BCL- $\mathrm{X}_{\mathrm{L}}$ inhibitor sensitized PIK3CA mutant TNBC cells to doxorubicin and etoposide (Fig. $7 \mathrm{H}$ and fig. S6C). MCL-1 plus BCL- $\mathrm{X}_{\mathrm{L}}$ inhibition also sensitized HER2 ${ }^{+}$breast cancer cells to lapatinib, a small-molecule HER2 kinase inhibitor that drives BIM-dependent apoptosis (Fig. 7I and fig. S6D) (37). Finally, consistent with the observation that tamoxifen and fulvestrant are weak inducers of apoptosis in vitro, we failed to observe cooperation between these drugs and MCL-1 plus BCL- $\mathrm{X}_{\mathrm{L}}$ inhibition in estrogen receptor ${ }^{+}$breast cancer cells (fig. S6E) (38). Collectively, these results demonstrate that apoptosis induction by standard-of-care chemotherapies is often enhanced through inhibition of the BCL- $\mathrm{X}_{\mathrm{L}}$ and $\mathrm{mTOR} / \mathrm{MCL}-1$ axes.

Finally, we investigated two observations arising from recent studies in the literature relevant to the findings presented here. First, a recent study described synergy between BEZ235 and ABT737 using elegant ovarian cancer spheroid culture models and then extended these findings to three breast cancer cell lines (39). The authors proposed that synergy between these agents in ovarian cancer cells was a result of up-regulation of BCL-2 after treatment with BEZ235, suggesting that the same mechanism may explain the observed synergy in breast cancer cells. We probed lysates from breast cancer cells treated with either vehicle or BEZ235 for BCL-2 protein expression. This analysis revealed no increase in BCL-2 expression upon treatment with BEZ235 (figs. S3A and S6F). When considered alongside the fact that selective BCL-2 inhibition does not sensitize cells to BEZ235 (Fig. 2C), it can be concluded that the synergy between BEZ235 and ABT737 observed in breast cancer cells is independent of BCL-2. This distinction may be important because it implies that selective BCL-2 inhibitors would be unlikely to have activity in breast cancer when combined with mTORC1/2 inhibitors. Second, two recent studies have demonstrated synergy between direct MCL-1 and BCL- $\mathrm{X}_{\mathrm{L}}$ inhibitors in breast cancer cell lines $(27,40)$. To preliminarily assess the long-term activity of direct versus indirect MCL-1 targeting, we cultured PIK3CA mutant breast cancer cells with WEHI-539, A-1210477, BEZ235, WEHI-539 plus A-1210477, or WEHI-539 plus BEZ235. When combined with WEHI-539, indirect targeting of MCL-1 using BEZ235 stably suppressed growth for the entirety of the $\sim 130$-day culture period (fig. S6G). In contrast, direct targeting of MCL-1 in combination with $\mathrm{BCL}-\mathrm{X}_{\mathrm{L}}$ only delayed cellular outgrowth for $\sim 25$ days in culture, with a similar effect observed in PIK3CA WT cells (fig. S6, G and H). Although the mechanisms underlying this differential long-term activity are unclear, these data nevertheless suggest that indirect targeting of MCL-1 may be more efficacious than direct targeting of MCL-1 in combination with BCL- $\mathrm{X}_{\mathrm{L}}$ inhibitors.

\section{DISCUSSION}

By demonstrating that mTOR pathway inhibitors fail to induce efficient apoptosis in PIK3CA mutant breast cancers because of the redundant prosurvival role of $\mathrm{BCL}-\mathrm{X}_{\mathrm{L}}$, we provide a potential explanation for the modest responses observed in patients treated with these drugs (16-18). Furthermore, we demonstrate that the efficacy of these agents can be markedly improved in the PIK3CA mutant context, which represents around $35 \%$ of all breast cancers, through simultaneous inhibition of BCL- $\mathrm{X}_{\mathrm{L}}(41)$. This strategy yields tumor regressions using low doses of $\mathrm{mTOR}$ and BCL-2/BCL- $\mathrm{X}_{\mathrm{L}}$ inhibitors. For the case of BCL-2/BCL$\mathrm{X}_{\mathrm{L}}$ inhibitors, these doses are 5- to 12-fold lower than the equivalent doses required to cause dose-limiting thrombocytopenia in human and large animal models, which are important considerations given the dose-limiting toxicities observed in human clinical trials with these and related agents $(16,42,43)$. This evidence, coupled with the fact that various $\mathrm{mTORC1} / 2$ inhibitors as well as the BCL-2/BCL- $\mathrm{X}_{\mathrm{L}}$ inhibitor ABT263 are already in clinical trials, suggests that the findings described here may be well positioned for near-term translation $(16,17)$. This finding also adds to a body of recent literature describing approaches to sensitize PIK3CA mutant breast cancers to $\mathrm{PI} 3 \mathrm{~K} / \mathrm{mTOR}$ pathway inhibitors, for example, by using cyclin-dependent kinase 4 (CDK4)/ CDK6 inhibitors or by targeting multiple nodes within the pathway $(44,45)$. The fact that these recently described combination therapies target cell cycle regulation and growth signaling, respectively, whereas the strategy described here targets mitochondrial apoptosis suggests that future studies that directly compare or combine these distinct approaches are warranted.

Our studies also demonstrate that MCL-1 is regulated by capdependent translation downstream of the mTOR/4E-BP axis in PIK3CA mutant tumors and that, by contrast, cap-dependent MCL-1 translation 
is regulated independently of this axis in PIK3CA WT breast cancers, suggesting that alternative regulators of the eIF4F complex may be relevant therapeutic targets in this context $(15,33,46)$. Future studies that define
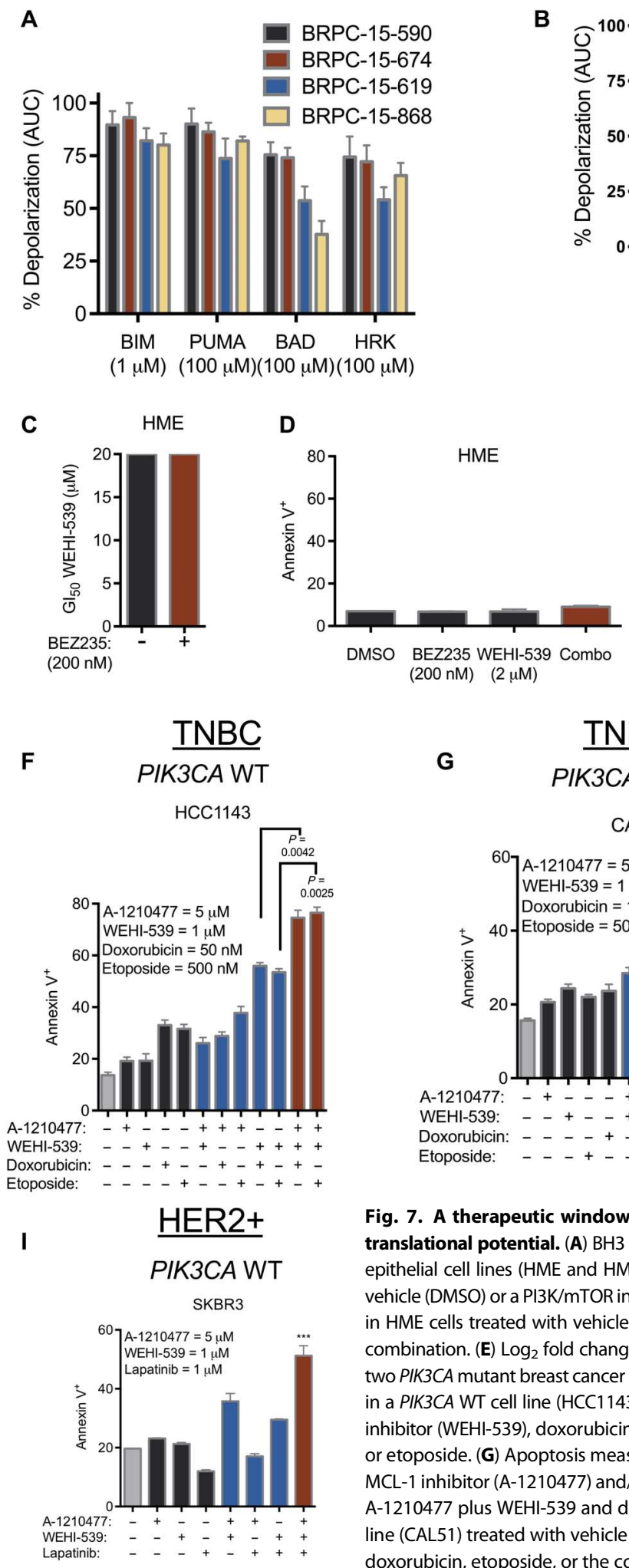

these targets and associated regulatory mechanisms are therefore of high interest because they may identify therapeutic strategies for targeting MCL-1 indirectly in the PIK3CA WT setting. Indirect MCL-1 targeting
B

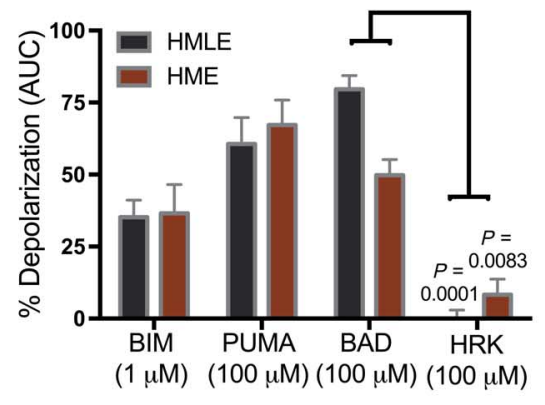

E

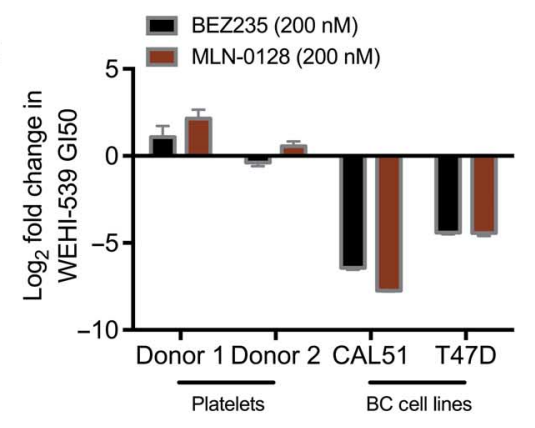

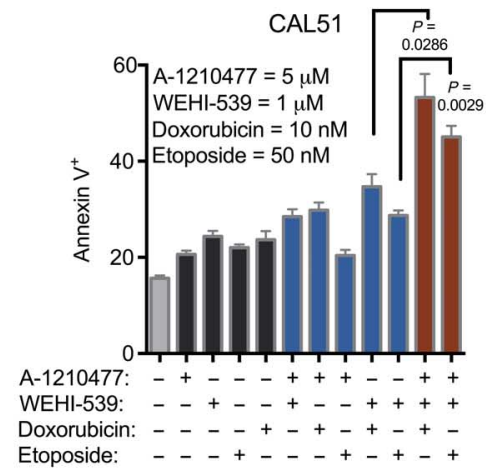

G

Fig. 7. A therapeutic window of combined $B C L-X_{L}$ and $M C L-1$ (direct or indirect) inhibition suggests translational potential. (A) BH3 profiling of four primary patient samples. (B) BH3 profiling of two normal breast epithelial cell lines (HME and HMLE). (C) $\mathrm{GI}_{50}$ value for a BCL- $\mathrm{X}_{\mathrm{L}}$ inhibitor (WEHI-539) in combination with either vehicle (DMSO) or a PI3K/mTOR inhibitor (BEZ235) in HME cells. (D) Apoptosis measurements by annexin $\mathrm{V}$ binding in HME cells treated with vehicle (DMSO), a PI3K/mTOR inhibitor (BEZ235), a BCL- $\mathrm{X}_{\mathrm{L}}$ inhibitor (WEHI-539), or the combination. (E) $\log _{2}$ fold change in $\mathrm{Gl}_{50}$ to WEHI-539 in platelets isolated from two independent donors and in two PIK3CA mutant breast cancer cell lines treated with vehicle, BEZ235, or MLN-0128. (F) Apoptosis measurements in a PIK3CA WT cell line (HCC1143) treated with vehicle (DMSO), an MCL-1 inhibitor (A-1210477) and/or a BCL-X inhibitor (WEHI-539), doxorubicin, etoposide, or the combination of A-1210477 plus WEHI-539 and doxorubicin or etoposide. (G) Apoptosis measurements in a PIK3CA mutant cell line (CAL51) treated with vehicle (DMSO), an MCL-1 inhibitor (A-1210477) and/or a BCL-X inhibitor (WEHI-539), doxorubicin, etoposide, or the combination of A-1210477 plus WEHI-539 and doxorubicin or etoposide. (H) Apoptosis measurements in a PIK3CA mutant cell line (CAL51) treated with vehicle (DMSO), a PI3K/mTOR inhibitor (BEZ235) and/or a BCL- $\mathrm{X}_{\mathrm{L}}$ inhibitor (WEHI-539), doxorubicin, etoposide, or the combination of the PI3K/mTOR plus BCL- $X_{L}$ inhibitors with either doxorubicin or etoposide. (I) Apoptosis measurements in a PIK3CA WT cell line (SKBR3) treated with vehicle (DMSO), an MCL-1 inhibitor (A-1210477) and/or a BCL-X inhibitor (WEHI-539), lapatinib, or the combination of the MCL-1 and BCL-X inhibitors with lapatinib. For all panels, error bars show data \pm SEM. For experiments in all panels, data are in $n=3$. 
strategies may be particularly important from a translational perspective because direct targeting of MCL-1 gives rise to rapid therapeutic resistance in vitro. Furthermore, there are currently no bioavailable inhibitors that have been demonsrated to target MCL-1 in humans, and a body of literature suggests that such agents may be difficult to tolerate owing to MCL-1's physiological essentiality, its role in hematopoietic stem cell survival, and its potential roles outside of mitochondrial apoptosis regulation $(47,48)$.

Finally, these results are particularly interesting in the context of TNBC, a disease subtype where therapeutic options are limited, because we have shown that dual inhibition of the mTOR/MCL-1 and BCL- $\mathrm{X}_{\mathrm{L}}$ axes promotes tumor regression in vivo while sensitizing these tumors to standard-of-care chemotherapies (49). Our findings may also be relevant in the setting of acquired resistance because recent reports suggest that breast cancers often acquire PIK3CA mutations during the development of resistance to first-line therapies, including endocrine therapies, suggesting that $\mathrm{mTOR}$ plus $\mathrm{BCL}-\mathrm{X}_{\mathrm{L}}$ inhibition may be a compelling therapeutic approach in this setting (50). More broadly, by defining key roles for MCL-1 and BCL- $\mathrm{X}_{\mathrm{L}}$ as selective regulators of the apoptotic network in breast cancer, this work lays the foundation for rational strategies built around direct or indirect inhibition of these targets in specific disease subtypes.

\section{MATERIALS AND METHODS Study design}

This study was designed to test the hypothesis that inhibition of pathways that affect cellular apoptotic priming, PI3K/mTOR and MAPK, has the potential to sensitize solid tumors to apoptosis induction by $\mathrm{BH} 3$ mimetics. We demonstrated in PIK3CA mutant breast cancers, using cellular models and in vivo orthotopic xenograft models, that the combination of $\mathrm{mTORC} 1 / 2$ inhibition with $\mathrm{BCL}-\mathrm{X}_{\mathrm{L}}$ inhibition suppresses growth and induces apoptosis. We showed in cellular models and patient samples that this is effective because of a lineage-encoded tumor dependency on MCL-1 (whose translation can be inhibited using mTORC1/2 inhibitors) and BCL- $\mathrm{X}_{\mathrm{L}}$. Sample sizes and $P$ values are indicated in the text, figure legends, or figures. For xenograft studies, using the sample size and power function in the JMP statistical software (SAS Institute Inc.), a group size of $n=7$ per treatment arm was estimated to be required to reliably detect a statistically relevant value $(P<0.05)$, by $50 \%$ change with $80 \%$ confidence, given the anticipated $30 \%$ variability for the tumor models used $(\alpha=0.05, \mathrm{SD}=0.3$, confidence of 0.8 , and $\mathrm{s} / \delta$ of 0.50 ). This estimate is based on one-way ANOVA followed by the Student-Newman-Keul's test and is in accordance with current literature in the field. Mice were randomized to treatment groups once tumors attained volumes of 0.17 to $0.25 \mathrm{~cm}^{3}$. The xenograft studies were not blinded.

\section{Xenograft tumor studies}

All procedures were performed as approved by the Institutional Animal Care and Use Committee at Duke University. Xenograft tumors were initiated in the axial mammary gland of female NU/NU mice by subcutaneous injection $\left(0.1 \mathrm{~cm}^{3}\right)$ of $3 \times 10^{6}$ BT-20 cells or $1 \times 10^{7}$ sgCtrl or sgMCL-1 MDA-MB-436 cells in a 1:1 mixture of serum-free medium and Matrigel (BD Biosciences). Tumors were measured three times weekly with calipers, and body weight and behavior were assessed at the time of measurement. Tumor volume was calculated as $A \times B^{2} \times$ 0.5 , where $A$ is the longer of perpendicular axes. When tumors attained 0.17 to $0.25 \mathrm{~cm}^{3}$ volume, mice were randomized to daily intraperitoneal injections of vehicle [10\% DMSO/90\% polyethylene glycol, molecular weight 400 (PEG-400)] or ABT737 (25 mg/kg), as well as daily gavage with vehicle (10\% N-methyl-pyrrolidinone/90\% PEG-400) or BEZ235 (10 mg/kg), or MLN-0128 (0.3 mg/kg). For sgCtrl and sgMCL-1, mice were randomized to daily intraperitoneal injection of vehicle $(10 \%$ DMSO/90\% PEG-400) or ABT737 (50 mg/kg). After 21 days of treatment, animals were euthanized and tumors were excised. Behavioral changes (hyperactivity) were noted in mice receiving ABT737 treatment. No major toxicities were observed in any of the treatment groups; however, if a mouse dropped $15 \%$ of its body weight, it was given a treatment holiday until the weight returned to the normal range. Tumor growth was analyzed (GraphPad Prism 6) by exponential growth curve analysis and by two-way ANOVA of matched values followed by Bonferroni multiple comparisons test to establish significance $(P<0.05)$ of the difference between groups at each day of treatment. Data for waterfall plots were calculated as percent change in tumor volume as compared to the size at the initiation of treatment.

\section{Statistical analysis of breast cancer subtypes}

Pearson's $\chi^{2}$ test was performed on the mutation status of each gene from table S1 under the null hypothesis that the joint probability distribution of the cell counts in a $2 \mathrm{D}$ contingency table is the product of the row and column marginals. $P$ values were obtained by simulation using mutation binary data $(1=\mathrm{WT}$ and $0=$ mutant $)$. Simulation was done by random sampling from each specific contingency table with given marginals, where the sampled marginals were strictly positive. A robust $P$ value was then computed using the Monte Carlo test with 10,000 iterations. A significance level of $\alpha=0.05$ represents the probability of obtaining a type 1 error (false positives).

\section{Statistical analysis}

Unless otherwise specified, Student's $t$ tests or, for grouped analyses, one-way ANOVA with Tukey's post hoc test was performed, and $P<$ 0.05 was considered significant. Results are presented as means \pm SEM.

\section{SUPPLEMENTARY MATERIALS}

www.sciencetranslationalmedicine.org/cgi/content/full/8/369/369ra175/DC1 Materials and Methods

Fig. S1. Solid tumors can be sensitized to BH3 mimetics.

Fig. S2. Breast cancer cell lines were stratified by genotype and histological subtype. Fig. S3. Direct inhibition of MCL-1 phenocopies PI3K pathway inhibition.

Fig. S4. MCL-1 is not regulated transcriptionally or posttranslationally by $\mathrm{PI} 3 \mathrm{~K} / \mathrm{mTOR}$. Fig. S5. PIK3CA WT breast cancers respond to direct MCL-1 inhibition.

Fig. S6. MCL-1 and BCL- $\mathrm{X}_{\mathrm{L}}$ targeting has therapeutic potential.

Table S1. Molecular and histological characteristics of the breast cancer cell lines from fig. S2C. Table S2. Sequences of shRNA clones.

Table S3. Raw tumor measurements for xenograft studies (provided as an Excel file). Table S4. Sequences of sgRNA clones.

Table S5. ER status, HER2 status, and PIK3CA mutation status (when available) of patient samples.

References (51-57)

\section{REFERENCES AND NOTES}

1. D. Hanahan, R. A. Weinberg, Hallmarks of cancer: The next generation. Cell 144, 646-674 (2011).

2. G. I. Evan, K. H. Vousden, Proliferation, cell cycle and apoptosis in cancer. Nature 411, 342-348 (2001).

3. M. R. Lackner, T. R. Wilson, J. Settleman, Mechanisms of acquired resistance to targeted cancer therapies. Future Oncol. 8, 999-1014 (2012).

4. L. Bai, S. Wang, Targeting apoptosis pathways for new cancer therapeutics. Annu. Rev. Med. 65, 139-155 (2014). 
5. W. J. Placzek, J. Wei, S. Kitada, D. Zhai, J. C. Reed, M. Pellecchia, A survey of the antiapoptotic $\mathrm{BCl}-2$ subfamily expression in cancer types provides a platform to predict the efficacy of Bcl-2 antagonists in cancer therapy. Cell Death Dis. 1, e40 (2010).

6. A. G. Letai, Diagnosing and exploiting cancer's addiction to blocks in apoptosis. Nat. Rev. Cancer 8, 121-132 (2008).

7. H. Harada, S. Grant, Targeting the regulatory machinery of BIM for cancer therapy. Crit. Rev. Eukaryot. Gene Expr. 22, 117-129 (2012).

8. M. Certo, V. Del Gaizo Moore, M. Nishino, G. Wei, S. Korsmeyer, S. A. Armstrong, A. Letai, Mitochondria primed by death signals determine cellular addiction to antiapoptotic BCL-2 family members. Cancer Cell 9, 351-365 (2006).

9. D. V. Baev, J. Krawczyk, M. O'Dwyer, E. Szegezdi, The BH3-mimetic ABT-737 effectively kills acute myeloid leukemia initiating cells. Leuk. Res. Rep. 3, 79-82 (2014).

10. A. W. Roberts, J. F. Seymour, J. R. Brown, W. G. Wierda, T. J. Kipps, S. L. Khaw, D. A. Carney, S. Z. He, D. C. S. Huang, H. Xiong, Y. Cui, T. A. Busman, E. M. McKeegan, A. P. Krivoshik, S. H. Enschede, R. Humerickhouse, Substantial susceptibility of chronic lymphocytic leukemia to BCL2 inhibition: Results of a phase I study of navitoclax in patients with relapsed or refractory disease. J. Clin. Oncol. 30, 488-496 (2012).

11. A. W. Roberts, M. S. Davids, J. M. Pagel, B. S. Kahl, S. D. Puvvada, J. F. Gerecitano T. J. Kipps, M. A. Anderson, J. R. Brown, L. Gressick, S. Wong, M. Dunbar, M. Zhu, M. B. Desai, E. Cerri, S. Heitner Enschede, R. A. Humerickhouse, W. G. Wierda, J. F. Seymour, Targeting BCL2 with venetoclax in relapsed chronic lymphocytic leukemia. N. Engl. J. Med. 374, 311-322 (2016).

12. R. Pan, L. J. Hogdal, J. M. Benito, D. Bucci, L. Han, G. Borthakur, J. Cortes, D. J. DeAngelo, L. Debose, H. Mu, H. Döhner, V. I. Gaidzik, I. Galinsky, L. S. Golfman, T. Haferlach, K. G. Harutyunyan, J. Hu, J. D. Leverson, G. Marcucci, M. Müschen, R. Newman, E. Park, P. P. Ruvolo, V. Ruvolo, J. Ryan, S. Schindela, P. Zweidler-McKay, R. M. Stone, H. Kantarjian, M. Andreeff, M. Konopleva, A. G. Letai, Selective BCL-2 inhibition by ABT-199 causes ontarget cell death in acute myeloid leukemia. Cancer Discov. 4, 362-375 (2014).

13. A. C. Faber, A. F. Farago, C. Costa, A. Dastur, M. Gomez-Caraballo, R. Robbins, B. L. Wagner, W. M. Rideout III, C. T. Jakubik, J. Ham, E. J. Edelman, H. Ebi, A. T. Yeo, A. N. Hata, Y. Song, N. U. Patel, R. J. March, A. T. Tam, R. J. Milano, J. L. Boisvert, M. A. Hicks, S. Elmiligy, S. E. Malstrom, M. N. Rivera, H. Harada, B. E. Windle, S. Ramaswamy, C. H. Benes, T. Jacks, J. A. Engelman, Assessment of ABT-263 activity across a cancer cell line collection leads to a potent combination therapy for small-cell lung cancer. Proc. Natl. Acad. Sci. U.S.A. 112, E1288-E1296 (2015).

14. A. N. Hata, J. A. Engelman, A. C. Faber, The BCL2 family: Key mediators of the apoptotic response to targeted anticancer therapeutics. Cancer Discov. 5, 475-487 (2015).

15. K. Fernald, M. Kurokawa, Evading apoptosis in cancer. Trends Cell Biol. 23, 620-633 (2013).

16. D. A. Fruman, C. Rommel, PI3K and cancer: Lessons, challenges and opportunities. Nat. Rev. Drug Discov. 13, 140-156 (2014)

17. J. Rodon, R. Dienstmann, V. Serra, J. Tabernero, Development of PI3K inhibitors: Lessons learned from early clinical trials. Nat. Rev. Clin. Oncol. 10, 143-153 (2013).

18. C. Massacesi, E. di Tomaso, P. Urban, C. Germa, N. Fretault, B. Bharani-Dharan, R. Tavorath, C. Quadt, C. Coughlin, S. Hirawat, Overcoming phosphatidylinositol 3-kinase (PI3K) activation in breast cancer: Emerging PI3K inhibitors. J. Oncopathol. 3, 27-39 (2015).

19. T. N. Chonghaile, J. E. Roderick, C. Glenfield, J. Ryan, S. E. Sallan, L. B. Silverman, M. L. Loh, S. P. Hunger, B. Wood, D. J. DeAngelo, R. Stone, M. Harris, A. Gutierrez, M. A. Kelliher, A. Letai, Maturation stage of T-cell acute lymphoblastic leukemia determines BCL-2 versus BCL-XL dependence and sensitivity to ABT-199. Cancer Discov. 4, 1074-1087 (2014)

20. T. Oltersdorf, S. W. Elmore, A. R. Shoemaker, R. C. Armstrong, D. J. Augeri, B. A. Belli, M. Bruncko, T. L. Deckwerth, J. Dinges, P. J. Hajduk, M. K. Joseph, S. Kitada, S. J. Korsmeyer, A. R. Kunzer, A. Letai, C. Li, M. J. Mitten, D. G. Nettesheim, S. Ng, P. M. Nimmer, J. M. O'Connor, A. Oleksijew, A. M. Petros, J. C. Reed, W. Shen, S. K. Tahir, C. B. Thompson, K. J. Tomaselli, B. Wang, M. D. Wendt, H. Zhang, S. W. Fesik, S. H. Rosenberg, An inhibitor of $\mathrm{BCl}-2$ family proteins induces regression of solid tumours. Nature 435, 677-681 (2005).

21. R. B. Corcoran, K. A. Cheng, A. N. Hata, A. C. Faber, H. Ebi, E. M. Coffee, P. Greninger, R. D. Brown, J. T. Godfrey, T. J. Cohoon, Y. Song, E. Lifshits, K. E. Hung, T. Shioda, D. Dias-Santagata, A. Singh, J. Settleman, C. H. Benes, M. Mino-Kenudson, K.-K. Wong, J. A. Engelman, Synthetic lethal interaction of combined BCL-XL and MEK inhibition promotes tumor regressions in KRAS mutant cancer models. Cancer Cell 23, 121-128 (2013).

22. K. A. Sarosiek, X. Chi, J. A. Bachman, J. J. Sims, J. Montero, L. Patel, A. Flanagan, D. W. Andrews, P. Sorger, A. Letai, BID preferentially activates BAK while BIM preferentially activates BAX, affecting chemotherapy response. Mol. Cell 51, 751-765 (2013).

23. G. J. Gores, S. H. Kaufmann, Selectively targeting Mcl-1 for the treatment of acute myelogenous leukemia and solid tumors. Genes Dev. 26, 305-311 (2012).

24. A. Jebahi, M. Villedieu, C. Petigny-Lechartier, E. Brotin, M. H. Louis, E. Abeilard, F. Giffard, M. Guercio, M. Briand, P. Gauduchon, S. Lheureux, L. Poulain, PI3K/mTOR dual inhibitor NVPBEZ235 decreases $\mathrm{Mcl}-1$ expression and sensitizes ovarian carcinoma cells to $\mathrm{BCl}-\mathrm{x}_{\mathrm{L}}$-targeting strategies, provided that Bim expression is induced. Cancer Lett. 348, 38-49 (2014).
25. J. R. Mills, Y. Hippo, F. Robert, S. M. H. Chen, A. Malina, C.-J. Lin, U. Trojahn, H. G. Wendel, A. Charest, R. T. Bronson, S. C. Kogan, R. Nadon, D. E. Housman, S. W. Lowe, J. Pelletier, mTORC1 promotes survival through translational control of Mcl-1. Proc. Natl. Acad. Sci. U.S.A. 105, 10853-10858 (2008).

26. A. C. Faber, E. M. Coffee, C. Costa, A. Dastur, H. Ebi, A. N. Hata, A. T. Yeo, E. J. Edelman, Y. Song, A. T. Tam, J. L. Boisvert, R. J. Milano, J. Roper, D. P. Kodack, R. K. Jain, R. B. Corcoran, M. N. Rivera, S. Ramaswamy, K. E. Hung, C. H. Benes, J. A. Engelman, mTOR inhibition specifically sensitizes colorectal cancers with KRAS or BRAF mutations to BCL-2/BCL-XL inhibition by suppressing MCL-1. Cancer Discov. 4, 42-52 (2014).

27. J. D. Leverson, H. Zhang, J. Chen, S. K. Tahir, D. C. Phillips, J. Xue, P. Nimmer, S. Jin, M. Smith, Y. Xiao, P. Kovar, A. Tanaka, M. Bruncko, G. S. Sheppard, L. Wang, S. Gierke, L. Kategaya, D. J. Anderson, C. Wong, J. Eastham-Anderson, M. J. C. Ludlam, D. Sampath, W. J. Fairbrother, I. Wertz, S. H. Rosenberg, C. Tse, S. W. Elmore, A. J. Souers, Potent and selective small-molecule MCL-1 inhibitors demonstrate on-target cancer cell killing activity as single agents and in combination with ABT-263 (navitoclax). Cell Death Dis. 6 , e1590 (2015).

28. X. M. Ma, J. Blenis, Molecular mechanisms of mTOR-mediated translational control. Nat. Rev. Mol. Cell Biol. 10, 307-318 (2009).

29. C. C. Thoreen, S. A. Kang, J. W. Chang, Q. Liu, J. Zhang, Y. Gao, L. J. Reichling, T. Sim, D. M. Sabatini, N. S. Gray, An ATP-competitive mammalian target of rapamycin inhibitor reveals rapamycin-resistant functions of mTORC1. J. Biol. Chem. 284, 8023-8032 (2009).

30. Y. Y. Zaytseva, J. D. Valentino, P. Gulhati, B. M. Evers, mTOR inhibitors in cancer therapy. Cancer Lett. 319, 1-7 (2012).

31. F. Chiarini, C. Evangelisti, J. A. McCubrey, A. M. Martelli, Current treatment strategies for inhibiting mTOR in cancer. Trends Pharmacol. Sci. 36, 124-135 (2015).

32. D. Walsh, C. Perez, J. Notary, I. Mohr, Regulation of the translation initiation factor elF4F by multiple mechanisms in human cytomegalovirus-infected cells. J. Virol. 79, 8057-8064 (2005).

33. J. Pelletier, J. Graff, D. Ruggero, N. Sonenberg, Targeting the elF4F translation initiation complex: A critical nexus for cancer development. Cancer Res. 75, 250-263 (2015).

34. X. Liu, V. Ory, S. Chapman, H. Yuan, C. Albanese, B. Kallakury, O. A. Timofeeva, C. Nealon, A. Dakic, V. Simic, B. R. Haddad, J. S. Rhim, A. Dritschilo, A. Riegel, A. McBride, R. Schlegel, ROCK inhibitor and feeder cells induce the conditional reprogramming of epithelial cells. Am. J. Pathol. 180, 599-607 (2012).

35. B. Elenbaas, L. Spirio, F. Koerner, M. D. Fleming, D. B. Zimonjic, J. L. Donaher, N. C. Popescu, W. C. Hahn, R. A. Weinberg, Human breast cancer cells generated by oncogenic transformation of primary mammary epithelial cells. Genes Dev. 15, 50-65 (2001).

36. T. Ni Chonghaile, K. A. Sarosiek, T.-T. Vo, J. A. Ryan, A. Tammareddi, G. Moore Vdel, J. Deng, K. C. Anderson, P. Richardson, Y.-T. Tai, C. S. Mitsiades, U. A. Matulonis, R. Drapkin, R. Stone, D. J. Deangelo, D. J. McConkey, S. E. Sallan, L. Silverman, M. S. Hirsch, D. R. Carrasco, A. Letai, Pretreatment mitochondrial priming correlates with clinical response to cytotoxic chemotherapy. Science 334, 1129-1133 (2011).

37. A. C. Faber, R. B. Corcoran, H. Ebi, L. V. Sequist, B. A. Waltman, E. Chung, J. Incio, S. R. Digumarthy, S. F. Pollack, Y. Song, A. Muzikansky, E. Lifshits, S. Roberge, E. J. Coffman, C. H. Benes, H. L. Gomez, J. Baselga, C. L. Arteaga, M. N. Rivera, D. Dias-Santagata, R. K. Jain, J. A. Engelman, BIM expression in treatment-naïve cancers predicts responsiveness to kinase inhibitors. Cancer Discov. 1, 352-365 (2011).

38. R. L. Sutherland, M. D. Green, R. E. Hall, R. R. Reddel, I. W. Taylor, Tamoxifen induces accumulation of MCF 7 human mammary carcinoma cells in the G0/G1 phase of the cell cycle. Eur. J. Cancer Clin. Oncol. 19, 615-621 (1983).

39. T. Muranen, L. M. Selfors, D. T. Worster, M. P. Iwanicki, L. Song, F. C. Morales, S. Gao, G. B. Mills, J. S. Brugge, Inhibition of PI3K/mTOR leads to adaptive resistance in matrixattached cancer cells. Cancer Cell 21, 227-239 (2012).

40. C. M. Goodwin, O. W. Rossanese, E. T. Olejniczak, S. W. Fesik, Myeloid cell leukemia-1 is an important apoptotic survival factor in triple-negative breast cancer. Cell Death Differ. 22, 2098-2106 (2015).

41. Cancer Genome Atlas Network, Comprehensive molecular portraits of human breast tumours. Nature 490, 61-70 (2012).

42. J. D. Leverson, D. C. Phillips, M. J. Mitten, E. R. Boghaert, D. Diaz, S. K. Tahir, L. D. Belmont, P. Nimmer, Y. Xiao, X. M. Ma, K. N. Lowes, P. Kovar, J. Chen, S. Jin, M. Smith, J. Xue, H. Zhang, A. Oleksijew, T. J. Magoc, K. S. Vaidya, D. H. Albert, J. M. Tarrant, N. La, L. Wang, Z.-F. Tao, M. D. Wendt, D. Sampath, S. H. Rosenberg, C. Tse, D. C. S. Huang, W. J. Fairbrother, S. W. Elmore, A. J. Souers, Exploiting selective BCL-2 family inhibitors to dissect cell survival dependencies and define improved strategies for cancer therapy. Sci. Transl. Med. 7, 279ra240 (2015).

43. C. Tse, A. R. Shoemaker, J. Adickes, M. G. Anderson, J. Chen, S. Jin, E. F. Johnson, K. C. Marsh, M. J. Mitten, P. Nimmer, L. Roberts, S. K. Tahir, Y. Xiao, X. Yang, H. Zhang, S. Fesik, S. H. Rosenberg, S. W. Elmore, ABT-263: A potent and orally bioavailable Bcl-2 family inhibitor. Cancer Res. 68, 3421-3428 (2008).

44. S. R. Vora, D. Juric, N. Kim, M. Mino-Kenudson, T. Huynh, C. Costa, E. L. Lockerman, S. F. Pollack, M. Liu, X. Li, J. Lehar, M. Wiesmann, M. Wartmann, Y. Chen, Z. A. Cao, 
M. Pinzon-Ortiz, S. Kim, R. Schlegel, A. Huang, J. A. Engelman, CDK 4/6 inhibitors sensitize PIK3CA mutant breast cancer to PI3K inhibitors. Cancer Cell 26, 136-149 (2014).

45. M. Elkabets, S. Vora, D. Juric, N. Morse, M. Mino-Kenudson, T. Muranen, J. Tao, A. B. Campos, J. Rodon, Y. H. Ibrahim, V. Serra, V. Rodrik-Outmezguine, S. Hazra, S. Singh, P. Kim, C. Quadt, M. Liu, A. Huang, N. Rosen, J. A. Engelman, M. Scaltriti, J. Baselga, mTORC1 inhibition is required for sensitivity to PI3K p110 inhibitors in PIK3CA-mutant breast cancer. Sci. Transl. Med. 5, 196ra199 (2013).

46. L. W. Thomas, C. Lam, S. W. Edwards, Mcl-1; the molecular regulation of protein function. FEBS Lett. 584, 2981-2989 (2010).

47. J. L. Rinkenberger, S. Horning, B. Klocke, K. Roth, S. J. Korsmeyer, Mcl-1 deficiency results in peri-implantation embryonic lethality. Genes Dev. 14, 23-27 (2000).

48. J. T. Opferman, H. Iwasaki, C. C. Ong, H. Suh, S-i. Mizuno, K. Akashi, S. J. Korsmeyer, Obligate role of anti-apoptotic MCL-1 in the survival of hematopoietic stem cells. Science 307, 1101-1104 (2005).

49. M. De Laurentiis, D. Cianniello, R. Caputo, B. Stanzione, G. Arpino, S. Cinieri, V. Lorusso, S. De Placido, Treatment of triple negative breast cancer (TNBC): Current options and future perspectives. Cancer Treat. Rev. 36 (Suppl. 3), S80-S86 (2010).

50. A. Markou, S. Farkona, C. Schiza, T. Efstathiou, S. Kounelis, N. Malamos, V. Georgoulias, E. Lianidou, PIK3CA mutational status in circulating tumor cells can change during disease recurrence or progression in patients with breast cancer. Clin. Cancer Res. 20, 5823-5834 (2014).

51. J. M. Uronis, T. Osada, S. McCall, X. Y. Yang, C. Mantyh, M. A. Morse, H. K. Lyerly, B. M. Clary, D. S. Hsu, Histological and molecular evaluation of patient-derived colorectal cancer explants. PLOS One 7, e38422 (2012).

52. K. C. Wood, D. J. Konieczkowski, C. M. Johannessen, J. S. Boehm, P. Tamayo, O. B. Botvinnik, J. P. Mesirov, W. C. Hahn, D. E. Root, L. A. Garraway, D. M. Sabatini, MicroSCALE screening reveals genetic modifiers of therapeutic response in melanoma. Sci. Signal. 5, rs4 (2012)

53. D. E. Root, N. Hacohen, W. C. Hahn, E. S. Lander, D. M. Sabatini, Genome-scale loss-offunction screening with a lentiviral RNAi library. Nat. Methods 3, 715-719 (2006).

54. O. Shalem, N. E. Sanjana, E. Hartenian, X. Shi, D. A. Scott, T. S. Mikkelsen, D. Heckl, B. L. Ebert, D. E. Root, J. G. Doench, F. Zhang, Genome-scale CRISPR-Cas9 knockout screening in human cells. Science 343, 84-87 (2014).

55. N. Y. Kalaany, D. M. Sabatini, Tumours with PI3K activation are resistant to dietary restriction. Nature 458, 725-731 (2009).

56. C. A. Martz, K. A. Ottina, K. R. Singleton, J. S. Jasper, S. E. Wardell, A. Peraza-Penton, G. R. Anderson, P. S. Winter, T. Wang, H. M. Alley, L. N. Kwong, Z. A. Cooper, M. Tetzlaff, P.-L. Chen, J. C. Rathmell, K. T. Flaherty, J. A. Wargo, D. P. McDonnell, D. M. Sabatini, K. C. Wood, Systematic identification of signaling pathways with potential to confer anticancer drug resistance. Sci. Signal. 7, ra121 (2014).
57. C. C. Thoreen, L. Chantranupong, H. R. Keys, T. Wang, N. S. Gray, D. M. Sabatini, A unifying model for mTORC1-mediated regulation of mRNA translation. Nature 485, 109-113 (2012).

Acknowledgments: We thank the members of the Wood and McDonnell laboratories for helpful discussions and technical assistance. We acknowledge G. Haas and C. Yip, in particular, for technical assistance. We also thank C. Chaffer, L. Heasley, A. Berchuck, and D. Hsu for the cell lines. Finally, we thank $C$. Thoreen for insight into cap-dependent translation, the reagents necessary for the affinity purification assay, and technical assistance. Funding: This work was supported by Duke University School of Medicine start-up funds and by the Duke Cancer Institute (K.C.W.), a scholar award to K.C.W. from the NIH Building Interdisciplinary Research Careers in Women's Health Program (K12HD043446), a Golfers Against Cancer Research Award (K.C.W.), a Stewart Trust Fellowship (K.C.W.), a V Scholar Award from the V Foundation for Cancer Research (K.C.W.), a U.S. Department of Defense Breast Cancer Research Program Breakthrough Award (BC151664) (K.C.W), NSF Graduate Research Fellowships under grant no. DGE-1106401 (G.R.A.) and grant no. DGF-1106401 (L.C.), NIH National Research Service Awards (P.S.W. and D.P.N.), a Schlumberger Foundation Faculty for the Future fellowship (M.C.), and NIH/National Institute of Diabetes and Digestive and Kidney Diseases award DK48807 (D.P.M.). Any opinions, findings, and conclusions or recommendations expressed in this material are those of the authors(s) and do not necessarily reflect the views of the NSF or the NIH. Author contributions: Conceptualization: K.C.W. and G.R.A.; methodology: K.C.W., G.R.A., S.E.W., D.P.M., S.J.M., and K.L.B.; formal analysis: K.C.W., G.R.A., L.C., and S.E.W.; investigation: G.R.A., S.E.W., H.M.A., M.C., J.C.L., P.S.S., E.K.Z.-M., J.P.T., E.M.S., A.Y., D.P.N., V.H., R.S.S., and P.S.W.; writing of original draft: K.C.W. and G.R.A.; writing, review, and editing: all authors; funding acquisition: K.C.W. and D.P.M.; resources: K.C.W. and D.P.M; supervision: K.C.W. and D.P.M. Competing interests: The authors declare that they have no competing interests.

\section{Submitted 20 July 2016}

Resubmitted 6 September 2016

Accepted 5 October 2016

Published 14 December 2016

10.1126/scitranslmed.aae0348

Citation: G. R. Anderson, S. E. Wardell, M. Cakir, L. Crawford, J. C. Leeds, D. P. Nussbaum, P. S. Shankar, R. S. Soderquist, E. M. Stein, J. P. Tingley, P. S. Winter, E. K. Zieser-Misenheimer H. M. Alley, A. Yllanes, V. Haney, K. L. Blackwell, S. J. McCall, D. P. McDonnell, K. C. Wood PIK3CA mutations enable targeting of a breast tumor dependency through mTOR-mediated MCL-1 translation. Sci. Transl. Med. 8, 369ra175 (2016). 
Science

Translational Medicine

MIAAAS
PIK3CA mutations enable targeting of a breast tumor dependency through mTOR-mediated MCL-1 translation Grace R. Anderson, Suzanne E. Wardell, Merve Cakir, Lorin Crawford, Jim C. Leeds, Daniel P. Nussbaum, Pallavi S. Shankar, Ryan S. Soderquist, Elizabeth M. Stein, Jennifer P. Tingley, Peter S. Winter, Elizabeth K. Zieser-Misenheimer, Holly M. Alley, Alexander Yllanes, Victoria Haney, Kimberly L. Blackwell, Shannon J. McCall, Donald P. McDonnell and Kris C. Wood (December 14, 2016)

Science Translational Medicine 8 (369), 369ra175. [doi: 10.1126/scitranslmed.aae0348]

Editor's Summary

\section{Sneak attack on breast cancer's defense}

The usual goal of cancer treatment is to kill malignant cells, not just slow down their growth. A class of drugs called $\mathrm{BH} 3$ mimetics serves this purpose by inhibiting antiapoptotic proteins and thus helping drive the cells toward apoptosis (programmed cell death). MCL-1 is an antiapoptotic protein that is not targeted by currently bioavailable $\mathrm{BH} 3$ mimetics, and it is often responsible for resistance to these drugs. Anderson et al. have discovered that breast cancers with the commonly observed PIK3CA mutations can be treated with mTOR inhibitors to suppress MCL-1, leaving the cells vulnerable to BH3 mimetics and subsequent induction of apoptosis, both directly and in combination with chemotherapy.

The following resources related to this article are available online at http://stm.sciencemag.org. This information is current as of December 14, 2016.

Article Tools Visit the online version of this article to access the personalization and article tools:

http://stm.sciencemag.org/content/8/369/369ra175

\section{Supplemental Materials}

Permissions

\section{"Supplementary Materials" \\ http://stm.sciencemag.org/content/supp1/2016/12/12/8.369.369ra175.DC1}

Obtain information about reproducing this article: http://www.sciencemag.org/about/permissions.dtl

Science Translational Medicine (print ISSN 1946-6234; online ISSN 1946-6242) is published weekly, except the last week in December, by the American Association for the Advancement of Science, 1200 New York Avenue, NW, Washington, DC 20005. Copyright 2016 by the American Association for the Advancement of Science; all rights reserved. The title Science Translational Medicine is a registered trademark of AAAS. 